\title{
Bacterial Endophyte Community Dynamics in Apple (Malus domestica Borkh.) Germplasm and Their Evaluation for Scab Management Strategies
}

\author{
Shahid A. Padder 1,*, Sheikh Mansoor ${ }^{2, * \mathbb{D}}$, Sajad A. Bhat ${ }^{1}$, Tawseef Rehman Baba ${ }^{3}$, Rauoof Ahmad Rather ${ }^{4}$, \\ Saima M. Wani ${ }^{1}$, Simona Mariana Popescu ${ }^{5}$, Shakeela Sofi ${ }^{1}$, Malik Asif Aziz ${ }^{6}$, Daniel Ingo Hefft ${ }^{7}$ (D), \\ Othman M. Alzahrani ${ }^{8}$, Ahmed Noureldeen ${ }^{8}$ (D) and Hadeer Darwish ${ }^{9}$
}

check for updates

Citation: Padder, S.A.; Mansoor, S.; Bhat, S.A.; Baba, T.R.; Rather, R.A.; Wani, S.M.; Popescu, S.M.; Sofi, S.; Aziz, M.A.; Hefft, D.I.; et al. Bacterial Endophyte Community Dynamics in Apple (Malus domestica Borkh.)

Germplasm and Their Evaluation for Scab Management Strategies. J. Fungi 2021, 7, 923. https://doi.org/ 10.3390/jof7110923

Academic Editors: Antonieta De Cal, Inmaculada Larena and

Paloma Melgarejo

Received: 7 August 2021

Accepted: 21 September 2021

Published: 31 October 2021

Publisher's Note: MDPI stays neutral with regard to jurisdictional claims in published maps and institutional affiliations.

Copyright: (c) 2021 by the authors. Licensee MDPI, Basel, Switzerland. This article is an open access article distributed under the terms and conditions of the Creative Commons Attribution (CC BY) license (https:/ / creativecommons.org/licenses/by/ $4.0 /)$.
1 Division of Basic Sciences and Humanities, FoH, Sher-e-Kashmir University of Agricultural Sciences \& Technology of Kashmir, Srinagar 190025, Jammu and Kashmir, India; drsajadbhat@skuastkashmir.ac.in (S.A.B.); Drsaimams22@gmail.com (S.M.W.); Shakeelasofi1221@gmail.com (S.S.)

2 Division of Biochemistry, FBSc, SKUAST-J, Jammu 180009, Jammu and Kashmir, India

3 Division of Fruit Science, SKUAST-Kashmir, Srinagar 190025, Jammu and Kashmir, India; tawseefrehman27@gmail.com

4 Division of Environmental Sciences, FoH, Sher-e-Kashmir University of Agricultural Sciences \& Technology of Kashmir, Srinagar 190025, Jammu and Kashmir, India; rauoofahmad@gmail.com

5 Department of Biology and Environmental Engineering, University of Craiova, 13, A.I. Cuza, 200585 Craiova, Romania; popescu_simona83@yahoo.com

6 Division of Basic Sciences and Humanities FoA, Sher-e-Kashmir University of Agricultural Sciences \& Technology of Kashmir, Wadura Sopore 193201, Jammu and Kashmir, India; malikazizaa21@gmail.com

7 University Centre Reaseheath, Reaseheath College, Nantwich CW5 6DF, UK; daniel.hefft@reaseheath.ac.uk

8 Department of Biology, College of Science, Taif University, P.O. Box 110099, Taif 21944, Saudi Arabia; o.alzahrani@tu.edu.sa (O.M.A.); a.noureldeen@tu.edu.sa (A.N.)

9 Department of Biotechnology, College of Sciences, Taif University, P.O. Box 110099, Taif 21944, Saudi Arabia hadeer@tu.edu.sa

* Correspondence: shahidpadder@skuastkashmir.ac.in (S.A.P.); mansoorshafi21@gmail.com (S.M.)

\begin{abstract}
The large genetic evolution due to the sexual reproduction-mediated gene assortments and propensities has made Venturia inaequalis (causing apple scab) unique with respect to its management strategies. The resistance in apple germplasm against the scab, being controlled for by more than fifteen genes, has limited gene alteration-based investigations. Therefore, a biological approach of bacterial endophyte community dynamics was envisioned across the apple germplasm in context to the fungistatic behavior against $V$. inaequalis. A total of 155 colonies of bacterial endophytes were isolated from various plant parts of the apple, comprising 19 varieties, and after screening for antifungal behavior followed by morphological, ARDRA, and sequence analysis, a total of 71 isolates were selected for this study. The alpha diversity indices were seen to fluctuate greatly among the isolation samples in context to microflora with antifungal behavior. As all the isolates were screened for the presence of various metabolites and some relevant genes that directly or indirectly influence the fungistatic behavior of the isolated microflora, a huge variation among the isolated microflora was observed. The outstanding isolates showing highest percentage growth inhibition of $V$. inaequalis were exploited to raise a bio-formulation, which was tested against the scab prevalence in eight apple varieties under controlled growth conditions. The formulation at all the concentrations caused considerable reductions in both the disease severity and disease incidence in all the tested apple varieties. Red Delicious being most important cultivar of the northwestern Himalayas was further investigated for its biochemical behavior in formulation and the investigation revealed different levels of enzyme production, chlorophyll, and sugars against the non-inoculated control.
\end{abstract}

Keywords: scab; apple; endophytes; Venturia inaequalis; germplasm 


\section{Introduction}

Apple (Malus domestica Borkh) belongs to the plant family Rosaceae, which is comprised of more than 100 genera and 300 species across the world, most frequently established in temperate climates [1]. All across the globe, apples are concentrated in temperate and subtropical countries, with trivial production levels in hilly areas of tropical parts of the globe. The area in Jammu and Kashmir utilizes 136.54 thousand hectares for its apple production. Annual production reaches 1672.72 thousand metric tons and productivity of 12.50 tons per hectare [2,3].

Several fungal pathogens such as Venturia inequalis, Podosphaera leucotrichia, Alternaria mali, etc., cause a huge loss to the apple industry. Of these, V. inaequalis (Cooke) G. Wint causing apple scab is economically the most significant pathogen. It is known to cause economic injury levels in many apple-producing countries across the globe. In the Jammu and Kashmir state, this disease was reported in 1970s and ever since, it has caused havoc in the apple industry with the extent of fruit loss of up to $60 \%$, estimating an amount in hundreds of crores [4]. V. inequalis, being a heterothallic haploid ascomycete, reproduces both sexually and asexually [3-6]. The disease takes the severe form in regions in which recurrent rainfall through the spring seasons leads into ascospore emancipation and infection [5]. In spring, the predisposing factors such as temperature and moisture conditions are favorable and ascospores are both released and disseminated by wind to bring about epidemics. When an ascospore lands on a susceptible leaf or fruit, it form lesions, leading to the formation of mitospores (conidia), which are splashed by water or blown by wind to bring the secondary infection. The ascospore landing is marked by the switch from pathogen to saprophytic to the parasitic phase $[7,8]$. Many scab control strategies across the globe are aimed at protecting plants against primary infections through chemicalmediated management means [9]. As the disease is polycyclic in nature, multiple fungicide applications are needed to assess this disease [10]. It shall be noted that some limited research studies have managed to contain the disease by spraying only five chemical-based fungicidal compounds at critical growth stages of the crop [4,5]. Systemic fungicide sprays limited to seven in number have previously been able to contain the disease but due to the emergence of fungicide resistance in pathogens, these practices have become obsolete [6]. A recent survey in southeastern Europe has revealed the development of resistance in $V$. inaequalis against the potent fungicides dodine, pyraclostrobin, boscalid, difenoconazole, and cypradonil [11].

The modern horticultural practices demand chemical-centered strategies for phytopathogen management and emphasize alternative control measures focused on the use of products that induce resistance against the diseases [12], as the present pesticide intensive strategies have led to ecological degradation, inducing detrimental environmental effects beyond the huge effect on the economy of the farming community. One of the alternatives to these practices could be natural chemicals based on copper or sulfur, but due to their efficacy on pathogens as well as the advent of phytotoxicity apprehensions, these compounds have also had little impact on scab management strategies. One of the windows of management could be provided by the use of resistant cultivars but such cultivars are observed to be less popular due to their poor yield and consumer acceptance. Additionally, $V$. inaequalis possess huge genetic evolution on account of the sexual reproduction-mediated gene hodge-podges, which has resulted in the breakdown of major scab resistance gene $\mathrm{Vf}$ among its populations [13]. Despite huge spending on research centered on the biological control of phyto-pathogens across the world and regardless of well-founded publications on this topic, biological control remedies for apple scab are not in practice, except for a few limited investigations, e.g., the use of Cladosporium cladosporioides H39 to contain the scab in canopy [14] and priming mediated through fructans. Some other scanty studies on biological remedies of scabs have been conducted but these investigations have targeted the primary infection causing ascospores (overwintering) in litter and not the actively multiplying disease on canopy $[15,16]$. While apple endophytes have been used widely against apple scab in Germany, Belgium, the Netherlands, and Canada [17], the non-availability of 
convenient germplasm in these areas has limited such studies; in addition, these investigations have tested the fungal endophytes, which could face a serious challenge in the context of the changing climate scenario of the Jammu and Kashmir state. The endophytes in general are interesting entities for understanding the plant microbe interfaces that augment plant development and protect it from phytopathogens [18].

In contemplating global climate change and the elevated temperatures in the present investigated areas, the bacterial microflora has a larger role to play in future biological remedies for phytopathogens. Endophytes are more competent than their rhizospheric counterparts due to their huge diversity in well-established anabolic pathways, which has a direct bearing on its ability to be used as a successful tool in phytopathogen management strategies. Thus, the objective of this investigation was to visualize the bacterial endophyte community dynamics across the apple germplasm in the context of fungistatic behavior against $V$. inaequalis, as well as to test the hypothesis that potential antagonists as a formulation at different concentrations may affect the scab in the tree canopy of apple. The gene cascades that indirectly modulate the containment of phytopathogens of the host have also been studied in the current investigation.

\section{Materials and Methods}

\subsection{Sampling Area}

The four districts of the Kashmir valley (Jammu and Kashmir state, India), namely Anantnag (3984 km² area, 33.730N 75.150E, $1615.44 \mathrm{~m}$ elevation), Baramulla ( $4588 \mathrm{~km}^{2}$ area, 34.20N 74.340E, $1592.885 \mathrm{~m}$ elevation), Pulwama $\left(1090 \mathrm{~km}^{2}\right.$ area, $33.87160 \mathrm{~N} 74.89460 \mathrm{E}$, $1651.711 \mathrm{~m}$ elevation), and Shopian (612 $\mathrm{km}^{2}$ area, 33.720N 74.830E, 2057.095 m elevation) were surveyed. The area falls under temperate climate with an average annual temperature of $11.8^{\circ} \mathrm{C}$ and $2853 \mathrm{~mm}$ of rainfall.

\subsection{Sampling Methodology}

In order to isolate $V$. inaequalis, fully expanded apple leaves (counting from the 5th, 6th, and 7th tip) were collected from different apple varieties with scab symptoms of nearly black spots with a brown center, irregular margins on the upper surface, and subtle lesions with discrete margins on the lower surface were selected as per the protocol [7]. Isolation of the pathogen was carried out as previously reported by Machardy and Mansoor et al., $[7,16]$. The collected infected leaves were incubated at $21^{\circ} \mathrm{C}$ with wet paper towels under sterile conditions until sporulation appeared. Then, these sporulated leaves were cut into pieces of the size of approximately $5 \mathrm{~mm}$ and were surface sterilized with $70 \%$ ethanol for $1 \mathrm{~min}$ and 10\% sodium hypochlorite for $5 \mathrm{~min}$, followed by three washings in sterile distilled water. The sample pieces were dried and placed on potato dextrose agar media, after which the plates were incubated at $21^{\circ} \mathrm{C}$ and mycelium was transferred on fresh potato dextrose agar (PDA) plates a checked for purity. The conidia were observed under microscope to identify $V$. inaequalis as per the protocol explained by Sutton et al., [19]. The cultures were grown on potato dextrose agar (PDA) for 14 days for single spore isolation. The geminated spore containing petri plates were subjected to incubation at $21^{\circ} \mathrm{C}$ until sporulation and conidia were observed as described above. All the platings were done in triplicates.

\subsection{Pathogenicity on Detached Leaves}

$V$. inaequalis was grown on PDA plates for 14 days at $21{ }^{\circ} \mathrm{C}$. The conidia were washed from the plates using sterilized distilled water and the spore count of the order of $4 \times 10^{5} / \mathrm{mL}$ was adjusted using a hemocytometer. Counting from the $5 \mathrm{th}$, $6 \mathrm{th}$, and 7th tip, fully expanded leaves were collected from three-year-old different apple varieties (Red Delicious, Gala Redlum, Early Red One, Red Fuji, Gala Mast, Red Chief, and Summer Red) on the upper surface. A $100 \mu \mathrm{L}$ of the conidial suspension was placed on the scratched portion, the leaves were incubated for 14 days at $21^{\circ} \mathrm{C}$, and symptoms of the scab development were observed [16] Conidia were washed from the leaves and observed 
under microscope for their resemblance to $V$. inaequalis. The experiment was carried out in triplicates.

Fresh roots, twigs, and leaves of different apple varieties were collected in order to isolate bacterial endophytes. In order to reduce the chances of contamination, the plant materials looking afresh (free from any disease) were used for endophytic bacterial microfloral isolation.

\subsection{Isolation, Morphological Characterization, and Preservation of Bacterial Endophytes}

The surface sterilization technique [20] with some minor modifications was employed for isolating the bacterial endophytes. The samples (roots, twigs, and leaves) after surface disinfection were placed for grinding with sterile mortar and pestle, and then the ground samples were dissolved in phosphate buffer saline ( $1000 \mathrm{~mL}$ containing $1.44 \mathrm{~g} \mathrm{Na}_{2} \mathrm{HPO}_{4}$, $2.4 \mathrm{~g} \mathrm{KH}_{2} \mathrm{HPO}_{4}, 0.2 \mathrm{~g} \mathrm{KCl}$, and $8.0 \mathrm{~g} \mathrm{NaCl}$, and with a $\mathrm{pH}$ of 7.4). Ground plant material was then serially diluted and a volume of $100 \mu \mathrm{l}$ from apiece dilution of 10-2, 10-3, 10-6, and 10-9 was spread plated on solid growth media (trypticase soy agar, nutrient agar, and luria bertani agar), followed by an incubation at $37^{\circ} \mathrm{C}$ for a period of $24-72 \mathrm{~h}$. The experiment had three replications.

\subsection{V. inaequalis Inhibition upon Co-Cultivation with Bacterial Endophytes}

The full-grown bacterial endophytes ( $48 \mathrm{~h}$ old) on the nutrient agar Petri dishes were placed (as line streaks) on PDA at equal distances of $2.2 \mathrm{~cm}$ from the center of the $100 \times 15 \mathrm{~mm}$ Petri dish. A $5 \mathrm{~mm}$ disc taken from the 10-day-old $V$. inaequalis culture was placed at the center of the Petri dish as per the protocol of [21] with some modifications and the plates were incubated at $23{ }^{\circ} \mathrm{C}$. The plates without the bacterial endophytes were kept as the control. The experiment was repeated with three replications set for the experimental design.

The percent growth inhibition was calculated using the formula $\mathrm{Gv}-(\mathrm{Gv}+$ endo) $/ \mathrm{Gv}$ $\times 100$, where $G v$ is the daily growth rate of $V$. inaequalis alone over six days and Gv + endo is the daily growth rate of $V$. inaequalis cultivated together with an endophyte over the period of one week, as per the protocol of [22] with slight modifications. All the isolates with growth inhibition activity against $V$. inaequalis were selected for further study.

\subsection{Diversity Quantification and Molecular Characterization with $16 S$ rRNA and ARDRA Analysis}

Genomic DNA of the isolated bacterial endophytes was extracted by growing single bacterial colonies on their particular medium of isolation for $24 \mathrm{~h}$ at $37^{\circ} \mathrm{C}$ and then the procedure of DNA extraction [23] with some modifications was employed. For PCR amplification, a total volume of 5-10 $\mu \mathrm{L}$ of the aqueous phase (upper) was used as a source of the DNA template [23]. The remaining mixture was stored at $-20^{\circ} \mathrm{C}$. DNA amplification was performed for the $16 \mathrm{~S}$ rRNA region using the primers 27F, 'AGAGTTTGATCCTGGCTCAG$3^{\prime}$ and 1492R, and 5'-GGTTACCTTGTTAGGACTT-3 [24].

Restriction fragment length polymorphism relying on the restriction-mediated analysis of amplified $16 \mathrm{~S}$ rRNA coding DNA, i.e., amplified $16 \mathrm{~S}$ ribosomal DNA restriction analysis (ARDRA), was employed to distinguish the isolates prior to sequencing. The restriction digestion of amplified $16 \mathrm{~S}$ ribosomal DNA with RsaI and HhaI (Thermo Scientific) was conducted using the method of [25] with minor adjustments. All the procedures were performed in triplicates. The unique strains as evident from the ARDRA analysis were selected for sequencing. The nucleotide sequences were compared with the sequences from the NCBI database and sequences displaying $>99 \%$ homology were retrieved by the Nucleotide-Basic-Local-Alignment-Search-Tool (BLAST N) package, which is accessible through the server of the National Center for Biotechnology Information (NCBI) (www.ncbi.nlm.nih.gov/BLAST) (accessed on 7 August 2018). For the construction of the Neighbor Joining Tree, all the $16 \mathrm{~S}$ rDNA sequences obtained were trimmed, applying trim primers for mapped reads (only primer track and reads that hit the primer parameters were selected) using CLC software (QUAGEN Bioinformatics). Multiple cluster alignment 
and phylogenetic analysis were performed using MEGA software (v.10.2.6) based on the neighbor joining method using a 1000 repetition bootstrap. The diversity indices (alpha diversity) of the isolated taxonomic groups were calculated using EstimateS (v. 9.1.0). The phylogenetic analysis on distance tree results and graphics of the outstanding sequences were carried out against the GenBank database using the NCBI BLAST tool available at http:/ / blast.ncbi.nlm.gov / Blast.cgi (accessed on 7 August 2018).

\subsection{Plant Growth Promoting Activities}

2.7.1. In Vitro 1-Aminocyclopropane-1-carboxylic Acid (ACC) Deaminase Activity of Bacterial Endophytes

ACC deaminase activity of the isolated bacterial endophytic strains was determined by employing the method of Penrose and Glick [26]. ACC deaminase activity was determined through the colorimetric method and screening of the microflora was also done for the presence of the ACC deaminase gene (acdS). Both experiments were performed in triplicates.

\subsubsection{Detection of acdS (ACC Deaminase Gene)}

In order to amplify the ACC deaminase gene, the precise primers ACCDF, $5^{\prime}$-ATGTCA CTGTTGGAAAAGTTCGA-3' ${ }^{\prime}$ and ACCDR, and 5'-TCAGCCGTCC CTGTAATAGC-3' were designed. The genomic DNA of the isolated strains were used as a template in the reaction process of PCR. The temperature sets used for PCR amplification were: $95{ }^{\circ} \mathrm{C}$ for $5 \mathrm{~min}$ for the initial denaturation; 30 cycles of the denaturation; at $94{ }^{\circ} \mathrm{C}$ for $60 \mathrm{~s}$; annealing at $53{ }^{\circ} \mathrm{C}$ for $90 \mathrm{~s}$; and extension at $72{ }^{\circ} \mathrm{C}$ for $10 \mathrm{~min}$. The sequence of the obtained amplicons was checked against the GenBank database using the NCBI BLAST tool available at http:/ / blast.ncbi.nlm.gov / Blast.cgi (accessed on 24 July 2019).

\subsubsection{Biological Nitrogen Fixation Assay}

In order to identify nitrogen fixing bacteria, they were grown on minimal nitrogenfree media [27]. Two methodologies were used for the purpose of bacterial growth in nitrogen-free media (BNF) and PCR-based identification of the nifH gene (component II of nitrogenase enzyme). The bacterial strains were screened for the presence of the nifH gene and was carried out as follows: the degenerate primers nifH F2 $\left(5^{\prime}-\right.$ CAGAACACCATYATGGARATGG-3') and nifH R2 (5'-CGCCGAGSACGTC TAGAAG-3') were designed from available bacterial nifH gene sequences observed online, and amplification was done for some selected endophytic bacterial strains. The sequence of the amplicons were analyzed against the GenBank database using the NCBI BLAST tool available at http:/ / blast.ncbi.nlm.gov / Blast.cgi (accessed on 3 December 2019).

Within the method of bacterial growth in nitrogen-free media, the endophytic strains were observed by growing on minimal nitrogen-free media $[27,28]$. The growth of a particular strain on minimal nitrogen-free media specified the presence of a nitrogenfixing attribute.

\subsubsection{Phosphate Solubilization}

All isolates were grown in tryptic soy (TS) broth. Log-phase growing cells (O.D. 0.6) of each culture $(15 \mu \mathrm{L})$ were spotted on Pikovskaya's medium plates [29] and were incubated in triplicates at $28^{\circ} \mathrm{C}$ for $3-4$ days. The zone of solubilization was measured and colony size was also measured to calculate solubilization index by the formula: SI = colony diameter + halo-zone diameter/colony diameter [30]. To carry out the assay for phosphate estimation, the method given by [28] was employed with three replications. The soluble phosphorus formed was estimated calorimetrically. 


\subsubsection{Indole-3-acetic Acid (IAA) Production}

IAA production was assessed by Salkowski's method with minor modifications in the incubation period ( 2 days instead of 4 days) [31]. The standard curve ranging from $5 \mu \mathrm{g} / \mathrm{mL}$ to $300 \mu \mathrm{g} / \mathrm{mL}$ was used for calculating IAA production.

\subsubsection{Production of Ammonia and Hydrocyanic Acid}

For the detection of ammonia, the method of Demutskaya and Kalinichenko [32] with slight modifications (incubation of $72 \mathrm{~h}$ ) was employed. The freshly grown culture of bacterial strains (O.D. 0.6) were inoculated in $10 \mathrm{~mL}$ peptone water broth in triplicates and were incubated for $72 \mathrm{~h}$ at $30^{\circ} \mathrm{C}$. A volume of $0.5 \mathrm{~mL}$ of Nessler's reagent was added and the appearance of a yellow/brown color indicated ammonia production.

For hydrocyanic acid (HCN) detection, the method of Schippers [33] was adopted using Kings B medium supplemented with $0.44 \%$ of glycine. The experiment was carried out in triplicates. $\mathrm{HCN}$ production was detected with the transformation in color of the filter paper (plated above the streaked strains), which was previously dipped in $2 \%$ of $\mathrm{Na}_{2} \mathrm{CO}_{3}$ prepared in $0.05 \%$ of picric acid; the color change was observed visually from yellow to dark brown.

\subsubsection{Siderophore Estimation Using the Chrome-azurol-S (CAS) Liquid Assay Method}

For the detection of siderophores, the Chrome-azurol-S (CAS) method was employed. In this method, $0.1 \mathrm{~mL}$ of bacterial cell-free extract of the supernatant (obtained by inoculating $15 \mu \mathrm{L}$ of $3 \times 10^{9} \mathrm{CFU} / \mathrm{mL}$ log-phase cells (O.D. 0.6) into nutrient broth and after incubation ( $48 \mathrm{~h}$ ) was centrifuged for $15 \mathrm{~min}$ at 10,000 rpm) was mixed with Chrome-azurol$\mathrm{S}$ (CAS) solution $(0.5 \mathrm{~mL})$, along with the shuttle solution $(10 \mu \mathrm{L}$ of $0.2 \mathrm{M} 5$-sulfosalicylic acid), in triplicates. The contents were kept at room temperature (for $10 \mathrm{~min}$ ) and the change in color (to yellow) of the solution indicated the existence of siderophore production.

\subsubsection{Formulation Development}

For the formulation development, the top ten isolates based on their ability to arrest the growth of $V$. inaequalis were selected to develop the formulation. The compatibility of the isolates was checked against each other and then these endophytic bacterial isolates were characterized as per the procedures in Bergey's manual of determinative bacteriology [34]. Formulation was achieved by taking the log-phase bacterial cells and centrifuging at $12,000 \times g$ for $15 \mathrm{~min}$; the pellets were washed with autoclaved distilled water to remove the media components and finally the pellets were resuspended in sterile distilled water with concentrations of $0.5,1.0,1.5,2.0,2.5,3.0,3.5,4.0,4.5,5.0,10$, and $15 \%$. The suspension of pellets was diluted by 10 -folds before making the final concentrations in order to include the carrier materials to be tested in the future with the formulation.

\subsection{In Vivo Studies}

Effect of Isolated Cultures on the Disease Incidence and Severity on Leaves under Pot House Conditions

The plants of various varieties (three years old) of apple were procured from the Division of Fruit Science SKUAST-K, Shalimar Srinagar, and Lidder valley nurseries. These plants were grown in pot culture/controlled conditions and for this experiment, soil was autoclaved at $121{ }^{\circ} \mathrm{C}$ and with $15 \mathrm{psi}$ for $30 \mathrm{~min}$. The plant roots were treated with the selected bacterial strains by dipping the seedlings in separate concentrations of bacterial suspensions for half an hour. The control plants were dipped for the same time in sterile distilled water only. The foliar applications of all the concentrations were made by using a Honda Ltd. mechanical sprayer (droplet size of 325 microns) as per the recommended schedule of sprays for scab management. Spore suspension of the $V$. inaequalis with a density of $10^{6}$ spores $/ \mathrm{mL}$ was applied (30 days interval) as droplets on the whole plants in order to ensure the pathogen presence in the environment of the tested 
plants. Sterile distilled water was sprayed in the same way on the control plants instead of on the formulation.

The disease incidence and severity were recorded every three weeks by counting the number of infected leaves on young shoots and rosettes, and visually estimating their percentage diseased area. Observations were made for five randomized branches per plant and ten older leaves were evaluated for leaf scab [35] to estimate the disease incidence and severity using the following formula:

$\%$ disease incidence $=$ number of scabbed leaves $/$ total number of tested leaves $\times 100$.

The disease severity (S) depended upon the modified scale using the TownsendHeberger's formula, expressed as

$$
\mathrm{S}(\%)=\Sigma(\text { nivi }) / \mathrm{NV} \times 100
$$

where $\mathrm{n}$ is the degree of infection according to the following scale: $0=$ no attack, $1=1-3$ spots per leaf, and $2=$ more than three spots per leaf.

The experiment was carried out in a completely randomized design with five replications (five plants each treatment).

\subsection{Biochemical Alterations Post Endophyte Inoculation}

One month after inoculating the endophytic formulation, a total of eight leaves (at the third internode from the top of the plant) were randomly selected for the quantification of physiological and biochemical attributes (namely guaiacol peroxidase (GPOD), catalase (CAT), superoxide dismutase (SOD), ascorbic acid peroxidase (POD), esterase (EST), and acid phosphatase (ACP)) of the Red Delicious variety of apple. The method of Liu et al., [36] was employed and described fleetingly as follows: roughly $0.15 \mathrm{~g}$ (fresh leaf tissue) was homogenized in a pre-cooled mortar in $5 \mathrm{~mL}$ of phosphate buffer $(50 \mathrm{mmol} / \mathrm{L}, \mathrm{pH} 7.8)$ solution. The homogenate obtained was centrifuged at $11,000.00 \times \mathrm{g}$ for a period of $15 \mathrm{~min}$ at $5{ }^{\circ} \mathrm{C}$. The resulting supernatant was used to calculate the enzyme activity. For the POD assay, one unit (enzyme) was defined as the content of the enzyme, resulting in a $1 \%$ absorbance surge in $1 \mathrm{~min}$ at $470 \mathrm{~nm}$. CAT activity was determined by measuring the rate change of $\mathrm{H}_{2} \mathrm{O}_{2}$ absorbance in $1 \mathrm{~min}$ (at $240 \mathrm{~nm}$ ). For the SOD assay, one unit (enzyme) activity amounted to the content of the enzyme that resulted in the 50\% inhibition rate of nitroblue tetreazolium reduction. The ascorbic acid peroxidase (POD) activity was calculated as per the method of Nakano and Asada [37], and enzyme activity was stated as A290/min/g fresh mass. Esterase activity was estimated spectrophotometrically at $25^{\circ} \mathrm{C}$ using 2-napthylacetate as per the protocol of Radic and Pevalek-Kozlina [38]. It was calculated by observing the elevation in absorbance at $313 \mathrm{~nm}$ due to the formation of 2-napthol. The reaction mixture contained $1.0 \mathrm{~mL}$ of $100 \mathrm{mM}$ Tris (pH 7.4) and $15 \mu \mathrm{L}$ of $100 \mathrm{mM}$ 2-napthylacetate, and both were dissolved in methanol (absolute). For each measurement, $30 \mu \mathrm{L}$ of crude extract was used. The enzyme activity was expressed as $\mu \mathrm{mol}$ of hydrolyzed substrate per minute/mg protein. Acid phosphatase activity was measured by the procedure of Besford [39] and absorbance was measured at $420 \mathrm{~nm}$ as units/min/g fresh weight. The chlorophyll estimation was done on the same extract as discussed above and was measured as previously described by Walker [38]. The sugars, namely glucose and fructose, in the leaves were determined calorimetrically at $340 \mathrm{~nm}$ absorbance as per the method of Kunst-Wilson and Zajonc [40].

\subsection{Data Analysis}

All the experiments were conducted in a completely randomized design (CRD) and the experimental data are expressed as mean $\pm \mathrm{SD}$ from five separate observations/replications. Normality and homogeneity of the collected data was tested using Levene's Test in IBM SPSS Statistics 19.0 (SPSS, Inc., Chicago, IL, USA). Differences in the culturable fungistatic microflora against the $V$. inaequalis was assessed using the one-way analysis of variance 
technique. The principal component analysis (PCA) was estimated using XLSTAT (V 2021.1). The post hoc analysis of the data was carried out by Tukey's test.

\section{Results}

\subsection{Identification and Diversity of Isolated Endophytic Microflora}

A total of 155 colonies based on various colony characteristics, namely elevation, margin, color, and texture, were isolated from various plant parts of the apple plant, comprising 19 varieties (Table S1). After screening for antifungal behavior, followed by morphological, ARDRA, and sequence analysis, a total of 71 isolates pooled from all the sources belonging to 23 genera (Figure 1; Table S2) were selected for this study. The genera shared certain qualities among the different sampled parts, namely leaves, twigs, and roots, as presented in Figure 2. The phylogenetic tree based on the Neighbor Joining method of 16S rDNA gene sequences of isolated microflora is expressed in Figure 3. A total of $59.15 \%$ of the bacteria were observed to be gram-negative and $40.85 \%$ were gram-positive, thus the population isolated was dominated by gram-negative microflora. The Simpson diversity index was $0.8529,0.8933$, and 0.9216 in the sampled twigs, roots, and leaves, respectively. Similarly, the Shannon index was observed to be 1.855, 1.877, and 1.984 in the sampled twigs, roots, and leaves, respectively, and the Margalef index was 2.94, 2.551, and 3.806 in the sampled twigs, roots, and leaves, respectively. All the indices were measured with respect to fungistatic microflora against $\mathrm{V}$. inaequalis. The alpha diversity indices are presented in Figure 4.

\subsection{Population Dynamics among the Collected Samples}

The population of bacterial endophytes in twigs varied from $\log _{10} 4.70 \times 10^{5}$ to $\log _{10}$ $7.21 \times 10^{5}(\mathrm{cfu} / \mathrm{gFW})$, with the highest observed in Fenna and the lowest in Red Delicious. In the roots, the population varied from $\log _{10} 5.84 \times 10^{5}$ to $\log _{10} 8.27 \times 10^{5}(\mathrm{cfu} / \mathrm{gFW})$, with the highest observed in Maharaji and the lowest in Summer Red. In the leaves, the population varied from $\log _{10} 5.35 \times 10^{5}$ to $\log _{10} 7.83 \times 10^{5}(\mathrm{cfu} / \mathrm{gFW})$, with the highest observed in Maharaji and the lowest in Golden Delicious (Table S1).

\subsection{Antagonist Activity against V. inaequalis}

Screening of the isolates was conducted based on antifungal activity against V.inaequalis. Among all the isolates across the available apple plant germplasm, namely Red Delicious, Golden Delicious, Red Chief, Gala Redlum, Fuji Zehn Aztech, Maharaji, Red velox, Gala mast, Malus floribunda, Summer Red, Red Fuji, Priscella, Oregon Spur, Gavin, Lal Cider, Manchurian, Fenna, and Ambri, it was observed that a total of 71 isolated strains exhibited antifungal behavior expressed as a percentage of growth inhibition (PGI) against $V$. inaequalis, with the highest PGI exhibited by the isolate P. psychrophila strain DST28 $(96.35 \pm 0.03 \%)$, followed by the P. fragi strain DST29 $(91.25 \pm 0.11 \%)$, while the lowest PGI was exhibited by the isolate O. pectoris strain DST59 (11.25 $\pm 0.08 \%)$ (Table 1$)$. In the screening process, we found that the highest number of fungistatic bacterial strains were isolated from Golden Delicious, followed by Fenna, and the least were found from the variety Fuji Zehn Aztech and Gala Mast (Table S1). 


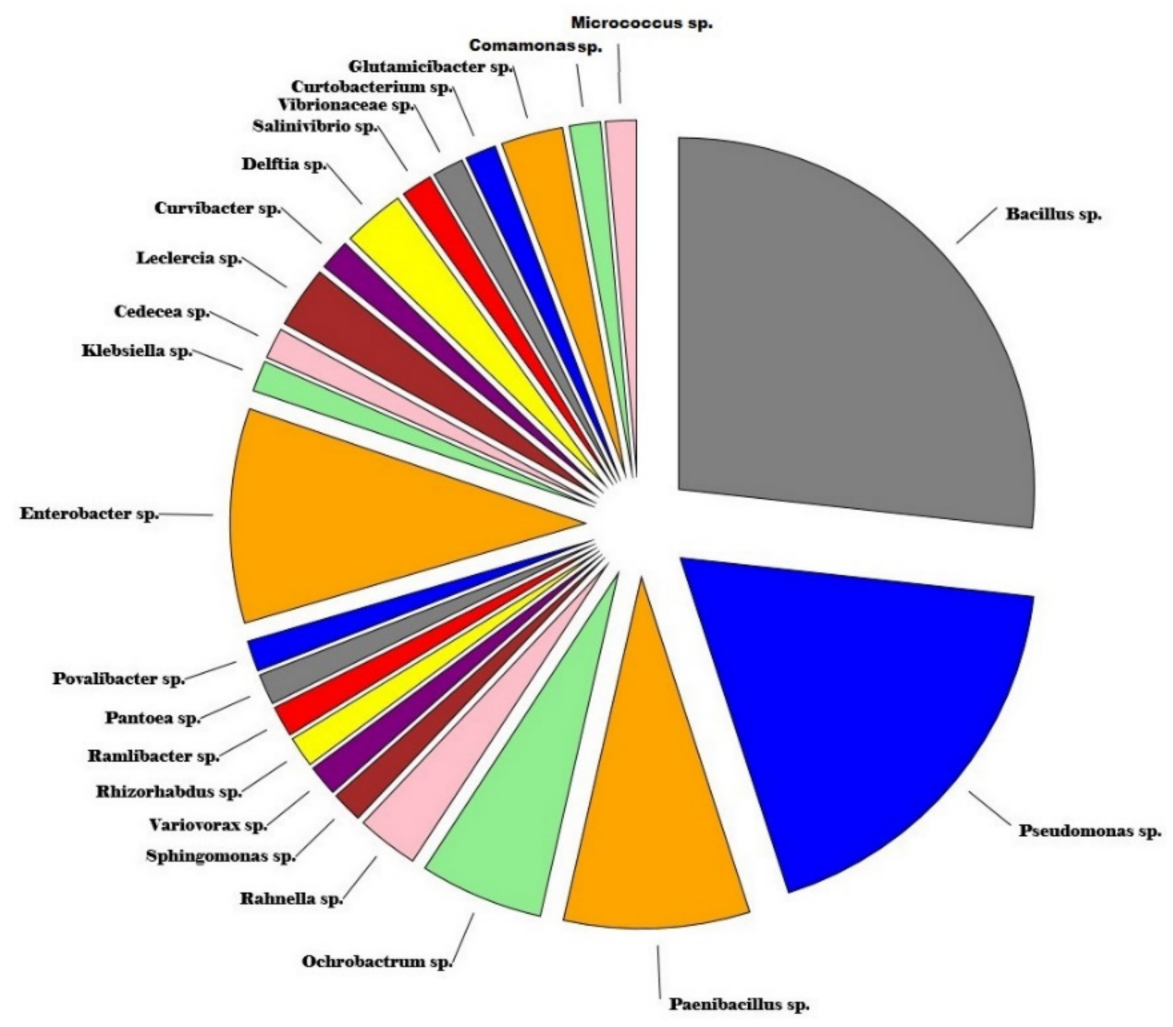

Figure 1. Distribution of the endophytic bacterial microflora distributed across apple germplasm (plant) having fungistatic attributes against the Venturia inaequalis. The genera are enumerated upon the ARDRA analysis of the $16 \mathrm{~S}$ rRNA coding sequences of the DNA.

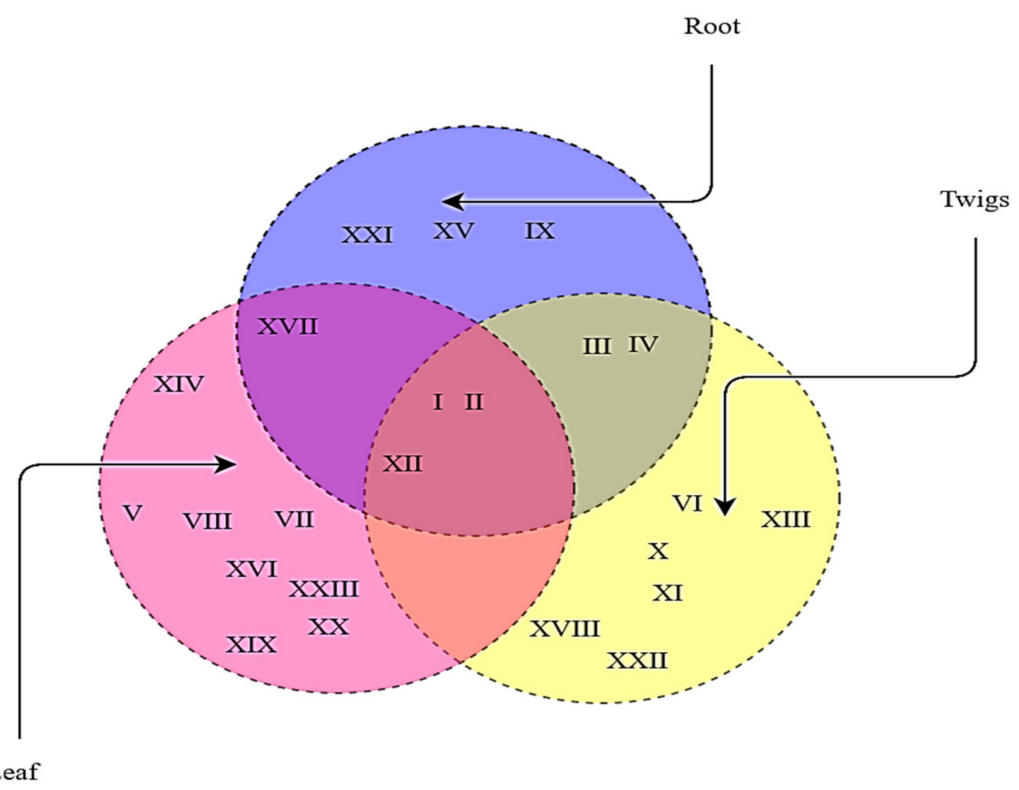

Figure 2. Venn diagram representing the various fungistatic microflora among the sampling plant parts. symbols in the Venn diagram represent the following: I, Bacillus sp.; II, Pseudomonas sp.; III, Paenibacillus sp.; IV, Ochrobactrum sp.; V, Rahnella sp.; Vi, Sphingomonas sp.; VII, Variovorax sp.; VIII, Rhizorhabdus sp.; IX, Ramlibacter sp.; X, Pantoea sp.; XI, Povalibacter sp.; XII, Enterobacter sp.; XIII, Klebsiella sp.; XIIV, Cedecea sp.; XV, Leclercia sp.; XVI, Curvibacter sp.; XVII, Delftia sp.; XVIII, Salinivibrio sp.; XIX, Vibrionaceae sp.; XX, Curtobacterium sp.; XXI, Glutamicibacter sp.; XXII, Comamonas sp.; and XXIII, Micrococcus sp. 


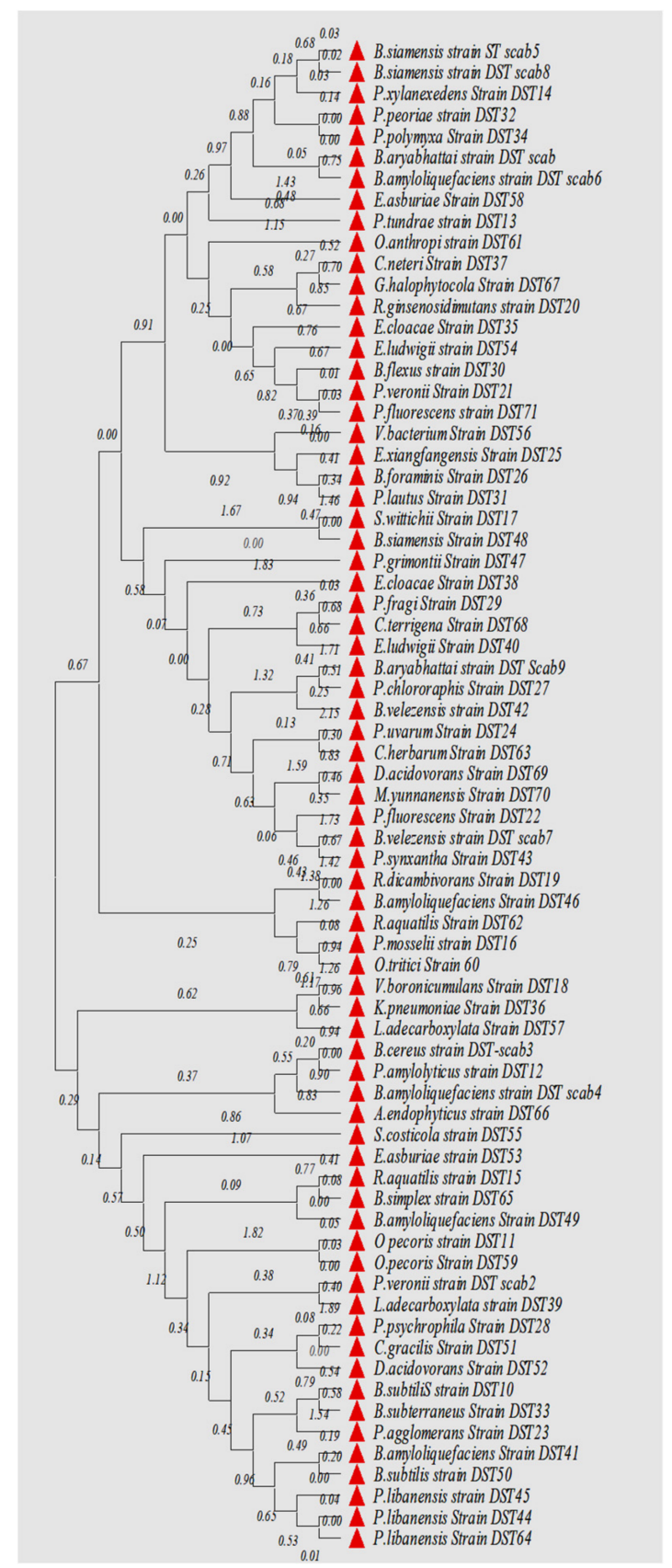

Figure 3. Phylogenetic tree based on the Neighbor Joining method of $16 \mathrm{~S}$ rDNA gene sequences of isolated microflora (endophytic) with fungistatic behavior isolated from various apple plant parts. The bootstrap consensus tree anecdotal from 1000 replicates is reserved and branches corresponding to partitions duplicated in less than $50 \%$ of the bootstrap replicates are collapsed. The evolutionary distances were computed using the p-distance method and are in the units of the number of base differences per site. The optimal tree with the sum of the branch length $=20.71250806$ is shown The confidence probability that the interior branch length is greater than 0 is estimated using the bootstrap test (shown next to the branches). This analysis involved 71 nucleotide sequences. Codon positions included were $1 \mathrm{st}+2 \mathrm{nd}+3 \mathrm{rd}+$ no-coding. All positions with less than $95 \%$ site coverage were eliminated, i.e., fewer than $5 \%$ of alignment gaps, missing data, and ambiguous bases were allowed at any position (partial deletion option). There were a total of 1389 positions in the final dataset. Evolutionary analysis was conducted in MEGA X (v. 10.2.6). 

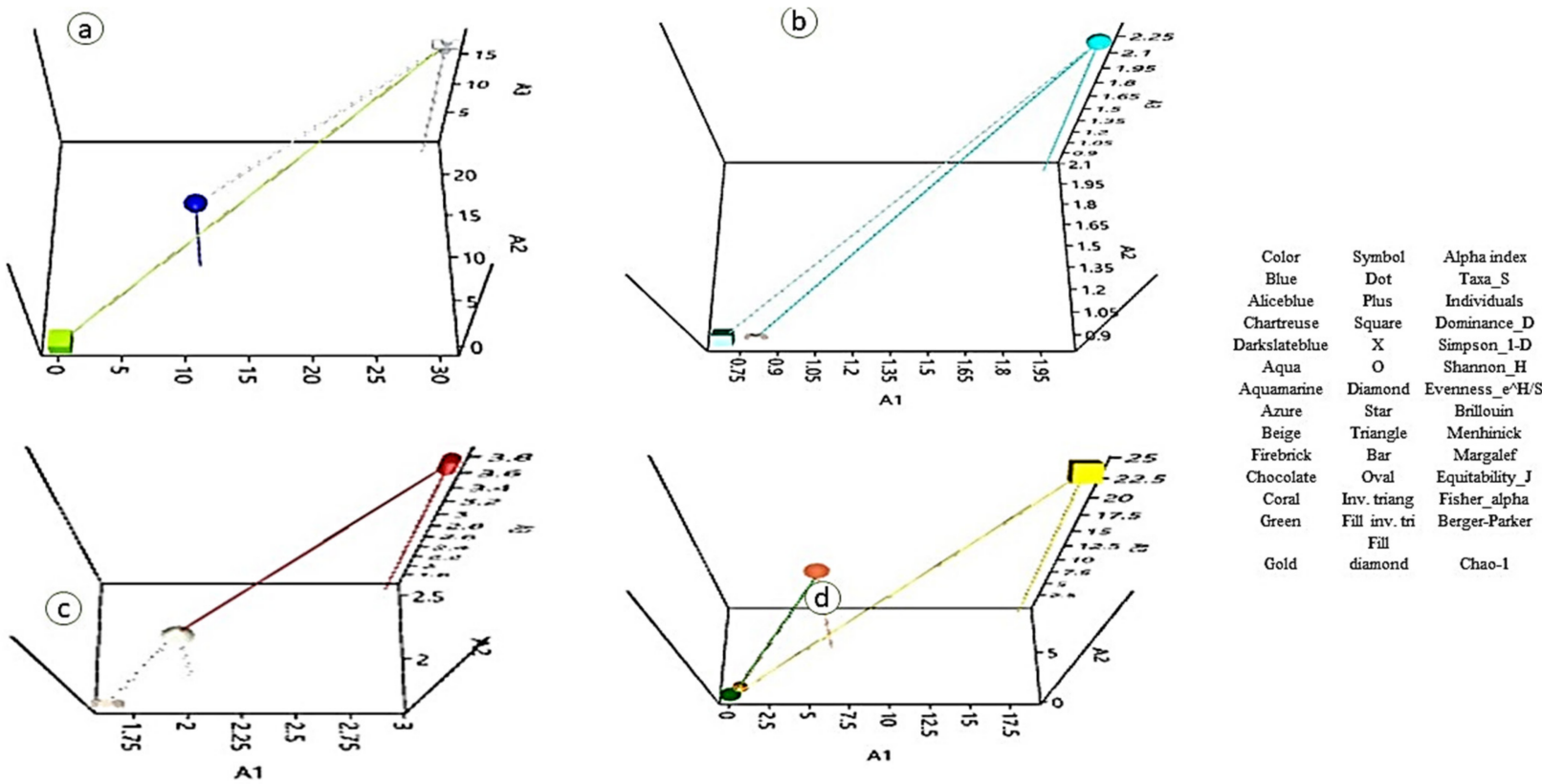

Gold

Figure 4. Alpha diversity indices ((a) Taxa S, individuals, and dominance; (b) Simpson, Shanon, and Evenness; (c) Brillouin, Menhinick, and Margalef; and (d) equitability, Fisher alpha, Berger Parker, and Chao-1) of the fungistatic microflora isolated from various plant parts across the apple germplasm. The diversity indices reflected a higher diversity in twigs (A1), followed by roots (A2) and leaves (A3) with respect to the presence of bacterial microflora fungistatic to Venturia inaequalis, as represented in the diagram.

Table 1. Magnitude of antifungal behavior and plant growth-promoting attributes of the isolated microflora.

\begin{tabular}{|c|c|c|c|c|c|}
\hline \multirow{2}{*}{ Strain } & \multirow{2}{*}{ PGI (\%) } & \multirow{2}{*}{ IAA $(\mu \mathrm{g} / \mathrm{mL})$} & \multicolumn{2}{|c|}{ Phosphate Solubilization } & \multirow{2}{*}{$\begin{array}{c}\text { ACC Deaminase } \\
\left(\mu \mathrm{M} \mathrm{mg} \mathrm{m}^{-1} \mathrm{~h}^{-1}\right)\end{array}$} \\
\hline & & & QS $(\mu \mathrm{g} / \mathrm{mL})$ & S. I. & \\
\hline DST scab & $81.95 \pm 0.03^{(\mathrm{F})}$ & $146.05 \pm 0.53^{(a)}$ & 0.00 & 0.00 & 0.00 \\
\hline DST scab2 & $54.75 \pm 0.12^{(X)}$ & $8.94 \pm 0.10$ (y) & $117.24 \pm 0.05^{(\mathrm{k})}$ & $1.67 \pm 0.07^{(\mathrm{e})}$ & 0.00 \\
\hline DST scab3 & $45.6 \pm 0.01^{(\mathrm{A} 6)}$ & $93.13 \pm 0.18^{(\mathrm{g})}$ & 0.00 & 0.00 & 0.00 \\
\hline DST scab4 & $82.55 \pm 0.07^{(\mathrm{E})}$ & 0.00 & $143.50 \pm 0.02^{(\mathrm{i})}$ & $2.30 \pm 0.22^{(b)}$ & $19.31 \pm 0.72^{(b)}$ \\
\hline DST scab5 & $67.4 \pm 0.18^{(\mathrm{O})}$ & $11.75 \pm 0.23^{(w)}$ & 0.00 & 0.00 & 0.00 \\
\hline DST scab6 & $45.20 \pm 0.09(\mathrm{~A} 6)$ & 0.00 & 0.00 & 0.00 & $8.07 \pm 0.12^{(g)}$ \\
\hline DST scab7 & $78.60 \pm 0.61^{(\mathrm{H})}$ & 0.00 & 0.00 & 0.00 & 0.00 \\
\hline DST scab8 & $66.2 \pm 0.83^{(\mathrm{P})}$ & $28.92 \pm 0.10^{(t)}$ & 0.00 & 0.00 & 0.00 \\
\hline DST Scab9 & $67.45 \pm 0.18^{(\mathrm{O})}$ & $31.76 \pm 0.83^{(r)}$ & 0.00 & 0.00 & $13.31 \pm 0.136^{(\mathrm{e})}$ \\
\hline DST10 & $50.10 \pm 0.08^{(\mathrm{A} 2)}$ & 0.00 & 0.00 & 0.00 & 0.00 \\
\hline DST11 & $24.35 \pm 0.45^{(\mathrm{h})}$ & 0.00 & $125.08 \pm 0.58^{(\mathrm{j})}$ & $2.20 \pm 0.09^{(b)}$ & 0.00 \\
\hline DST12 & $65.25 \pm 0.05^{(Q)}$ & 0.00 & 0.00 & 0.00 & 0.00 \\
\hline DST13 & $63.05 \pm 0.19^{(\mathrm{R})}$ & $49.03 \pm 0.63^{(n)}$ & 0.00 & 0.00 & 0.00 \\
\hline DST14 & $77.55 \pm 0.92^{(\mathrm{I})}$ & 0.00 & $218.04 \pm 0.06^{(b)}$ & 2.04. $\pm 0.53^{\text {(c) }}$ & 0.00 \\
\hline DST15 & $85.7 \pm 0.28^{(\mathrm{C})}$ & $15.82 \pm 0.13^{(\mathrm{v})}$ & 0.00 & 0.00 & $14.42 \pm 0.06^{(\mathrm{d})}$ \\
\hline DST16 & $58.01 \pm 0.13^{(\mathrm{U})}$ & $71.15 \pm 0.59^{(1)}$ & 0.00 & 0.00 & 0.00 \\
\hline DST17 & $66.07 \pm 0.01^{(\mathrm{P})}$ & 0.00 & 0.00 & 0.00 & 0.00 \\
\hline
\end{tabular}


Table 1. Cont.

\begin{tabular}{|c|c|c|c|c|c|}
\hline \multirow{2}{*}{ Strain } & \multirow{2}{*}{ PGI (\%) } & \multirow{2}{*}{ IAA $(\mu \mathrm{g} / \mathrm{mL})$} & \multicolumn{2}{|c|}{ Phosphate Solubilization } & \multirow{2}{*}{$\begin{array}{c}\text { ACC Deaminase } \\
\left(\mu \mathrm{M} \mathrm{mg} \mathrm{m}^{-1} \mathrm{~h}^{-1}\right)\end{array}$} \\
\hline & & & QS $(\mu \mathrm{g} / \mathrm{mL})$ & S. I. & \\
\hline DST18 & $58.40 \pm 0.07^{(\mathrm{U})}$ & $1.16 \pm 0.23^{(\mathrm{a} 1)}$ & $156.43 \pm 0.23(\mathrm{~g})$ & $2.18 \pm 0.03^{(b)}$ & 0.00 \\
\hline DST19 & $32.10 \pm 0.017^{(\mathrm{f})}$ & $44.18 \pm 0.39(\mathrm{p})$ & 0.00 & 0.00 & 0.00 \\
\hline DST20 & $45.35 \pm 0.10^{(\mathrm{A} 6)}$ & 0.00 & 0.00 & 0.00 & 0.00 \\
\hline DST21 & $54.75 \pm 0.01$ (y) & $29.98 \pm 0.17^{(\mathrm{s})}$ & $188.82 \pm 0.14^{(\mathrm{e})}$ & $2.52 \pm 0.09^{(a)}$ & 0.00 \\
\hline DST22 & $48.15 \pm 0.79$ (A3) & $41.29 \pm 0.05^{(\mathrm{q})}$ & $225.51 \pm 0.01^{\text {(a) }}$ & $1.93 \pm 0.15^{(\mathrm{d})}$ & 0.00 \\
\hline DST23 & $15.01 \pm 0.04^{(\mathrm{k})}$ & 0.00 & 0.00 & 0.00 & 0.00 \\
\hline DST24 & $71.85 \pm 0.13^{(\mathrm{M})}$ & 0.00 & 0.00 & 0.00 & $6.41 \pm 1.02^{(h)}$ \\
\hline DST25 & $23.80 \pm 0.43^{(\mathrm{i})}$ & 0.00 & 0.00 & 0.00 & 0.00 \\
\hline DST26 & $38.04 \pm 0.23^{(b)}$ & $77.52 \pm 0.04^{(\mathrm{j})}$ & $191.04 \pm 0.15^{(\mathrm{d})}$ & $2.15 \pm 0.19^{(b)}$ & 0.00 \\
\hline DST27 & $52.01 \pm 0.02(\mathrm{~A} 1)$ & 0.00 & 0.00 & 0.00 & 0.00 \\
\hline DST28 & $96.35 \pm 0.03^{(\mathrm{A})}$ & $48.25 \pm 0.19^{(\mathrm{o})}$ & 0.00 & 0.00 & $18.21 \pm 0.00^{(\mathrm{c})}$ \\
\hline DST29 & $91.25 \pm 0.11^{(\mathrm{B})}$ & $31.65 \pm 0.83^{(r)}$ & $151.13 \pm 0.09^{(h)}$ & $2.53 \pm 0.01^{(a)}$ & 0.00 \\
\hline DST30 & $50.25 \pm 0.40^{(\mathrm{A} 2)}$ & 0.00 & 0.00 & 0.00 & 0.00 \\
\hline DST31 & $13.05 \pm 0.19^{(1)}$ & $101.29 \pm 0.87^{(\mathrm{f})}$ & 0.00 & 0.00 & 0.00 \\
\hline DST32 & $75.19 \pm 0.00^{(\mathrm{K})}$ & $87.05 \pm 0.65^{(h)}$ & $162.54 \pm 0.03^{(f)}$ & $2.52 \pm 0.19^{(a)}$ & 0.00 \\
\hline DST33 & $83.05 \pm 0.42^{(\mathrm{D})}$ & 0.00 & 0.00 & 0.00 & 0.00 \\
\hline DST34 & $54.25 \pm 0.02^{(X)}$ & $71.96 \pm 0.69^{(\mathrm{k})}$ & 0.00 & 0.00 & 0.00 \\
\hline DST35 & $43.75 \pm 0.21^{(\mathrm{a})}$ & 0.00 & 0.00 & 0.00 & 0.00 \\
\hline DST36 & $80.85 \pm 0.49^{(G)}$ & $51.09 \pm 0.12^{(\mathrm{m})}$ & $124.23 \pm 0.09(\mathrm{j})$ & $1.85 \pm 0.07^{(\mathrm{d})}$ & 0.00 \\
\hline DST37 & $66.25 \pm 0.00^{(\mathrm{P})}$ & 0.00 & 0.00 & 0.00 & 0.00 \\
\hline DST338 & $46.06 \pm 0.36^{(\mathrm{A} 5)}$ & $81.65 \pm 0.03^{(\mathrm{i})}$ & 0.00 & 0.00 & 0.00 \\
\hline DST39 & $77.15 \pm 1.91^{(\mathrm{I})}$ & 0.00 & 0.00 & 0.00 & 0.00 \\
\hline DST40 & $68.08 \pm 0.17^{(\mathrm{N})}$ & 0.00 & 0.00 & 0.00 & 0.00 \\
\hline DST41 & $67.34 \pm 0.22^{(\mathrm{O})}$ & $123.07 \pm 0.14^{(b)}$ & 0.00 & 0.00 & 0.00 \\
\hline DST42 & $47.75 \pm 0.02(\mathrm{~A} 4)$ & $21.08 \pm 0.00^{(\mathrm{u})}$ & 0.00 & 0.00 & 0.00 \\
\hline DST43 & $23.75 \pm 0.09^{(\mathrm{i})}$ & 0.00 & 0.00 & 0.00 & 0.00 \\
\hline DST44 & $68.65 \pm 0.14^{(\mathrm{N})}$ & & 0.00 & 0.00 & 0.00 \\
\hline DST45 & $52.75 \pm 0.32^{(Z)}$ & 0.00 & $203.08 \pm 0.02^{(\mathrm{c})}$ & $1.93 \pm 0.06^{(\mathrm{d})}$ & 0.00 \\
\hline DST46 & $76.25 \pm 1.11^{(\mathrm{J})}$ & $11.16 \pm 0.27^{(\mathrm{x})}$ & 0.00 & 0.00 & 0.00 \\
\hline DST47 & $68.48 \pm 0.06^{(\mathrm{N})}$ & $117.17 \pm 1.30^{(\mathrm{c})}$ & 0.00 & 0.00 & 0.00 \\
\hline DST48 & $57.75 \pm 0.88^{(\mathrm{V})}$ & 0.00 & 0.00 & 0.00 & 0.00 \\
\hline DST49 & $67.75 \pm 0.02(\mathrm{O})$ & 0.00 & 0.00 & 0.00 & 0.00 \\
\hline DST50 & $57.04 \pm 0.11^{(\mathrm{V})}$ & 0.00 & 0.00 & 0.00 & $22.61 \pm 0.72^{(a)}$ \\
\hline DST51 & $37.45 \pm 0.09$ (c) & 0.00 & 0.00 & 0.00 & 0.00 \\
\hline DST52 & $45.16 \pm 0.52(\mathrm{~A} 6)$ & $2.25 \pm 0.06^{(\mathrm{z})}$ & 0.00 & 0.00 & 0.00 \\
\hline
\end{tabular}


Table 1. Cont.

\begin{tabular}{|c|c|c|c|c|c|}
\hline \multirow{2}{*}{ Strain } & \multirow{2}{*}{ PGI (\%) } & \multirow{2}{*}{ IAA $(\mu \mathrm{g} / \mathrm{mL})$} & \multicolumn{2}{|c|}{ Phosphate Solubilization } & \multirow{2}{*}{$\begin{array}{l}\text { ACC Deaminase } \\
\left(\mu \mathrm{M} \mathrm{mg} \mathrm{m}^{-1} \mathrm{~h}^{-1}\right)\end{array}$} \\
\hline & & & QS $(\mu \mathrm{g} / \mathrm{mL})$ & S. I. & \\
\hline DST53 & $55.75 \pm 0.28^{(\mathrm{W})}$ & 0.00 & 0.00 & 0.00 & 0.00 \\
\hline DST54 & $45.25 \pm 0.66^{(\mathrm{A} 6)}$ & 0.00 & 0.00 & 0.00 & 0.00 \\
\hline DST55 & $47.15 \pm 0.06^{(\mathrm{A} 4)}$ & $110.05 \pm 1.13^{(\mathrm{e})}$ & 0.00 & 0.00 & 0.00 \\
\hline DST56 & $67.25 \pm 0.26^{(\mathrm{O})}$ & $1.19 \pm 0.01^{(\mathrm{a} 1)}$ & 0.00 & 0.00 & 0.00 \\
\hline DST57 & $18.95 \pm 0.07^{(\mathrm{j})}$ & $81.54 \pm 0.73^{(\mathrm{i})}$ & 0.00 & 0.00 & 0.00 \\
\hline DST58 & $36.13 \pm 0.08^{(d)}$ & 0.00 & 0.00 & 0.00 & 0.00 \\
\hline DST59 & $11.25 \pm 0.08^{(1)}$ & 0.00 & 0.00 & 0.00 & 0.00 \\
\hline DST60 & $73.5 \pm 0.09^{(\mathrm{L})}$ & 0.00 & 0.00 & 0.00 & $11.91 \pm 0.36^{(\mathrm{f})}$ \\
\hline DST61 & $59.17 \pm 0.02^{(\mathrm{T})}$ & $71.59 \pm 1.12^{(\mathrm{kl})}$ & $102.16 \pm 0.05^{(\mathrm{m})}$ & $2.19 \pm 0.07^{(b)}$ & 0.00 \\
\hline DST62 & $46.15 \pm 0.05^{(\mathrm{A} 5)}$ & 0.00 & 0.00 & 0.00 & 0.00 \\
\hline DST63 & $18.25 \pm 0.16^{(j)}$ & 0.00 & 0.00 & 0.00 & 0.00 \\
\hline DST64 & $58.05 \pm 0.37^{(\mathrm{U})}$ & 0.00 & $115.65 \pm 0.01^{(1)}$ & $1.34 \pm 0.18^{(\mathrm{f})}$ & 0.00 \\
\hline DST65 & $38.25 \pm 0.14^{(b)}$ & 0.00 & 0.00 & 0.00 & 0.00 \\
\hline DST66 & $30.25 \pm 0.33^{(g)}$ & 0.00 & 0.00 & 0.00 & 0.00 \\
\hline ST67 & $62.22 \pm 0.18^{(S)}$ & $115.75 \pm 0.93^{(\mathrm{d})}$ & 0.00 & 0.00 & 0.00 \\
\hline DST68 & $53.75 \pm 0.02^{(Y)}$ & 0.00 & 0.00 & 0.00 & 0.00 \\
\hline DST69 & $33.75 \pm 0.16^{(\mathrm{e})}$ & $8.75 \pm 0.05^{(y)}$ & 0.00 & 0.00 & 0.00 \\
\hline DST70 & $63.19 \pm 0.07^{(\mathrm{R})}$ & 0.00 & 0.00 & 0.00 & $7.94 \pm 0.26^{(\mathrm{g})}$ \\
\hline DST71 & $47.25 \pm 0.81(\mathrm{~A} 4)$ & 0.00 & 0.00 & 0.00 & 0.00 \\
\hline
\end{tabular}

Subscripts indicate that within the column the values with same letters did not differ by Tukey's test.

\subsection{Assay for In Vitro Plant Growth Promotion of Indole-3-acetic Acid Production}

All the isolated bacterial strains were screened for their ability to produce auxin, i.e., IAA (Table 1). The culture supernatant of 32 isolates produced IAA. The IAA production varied from $1.16 \pm 0.23(\mu \mathrm{g} / \mathrm{mL})$ to $146.05 \pm 0.53(\mu \mathrm{g} / \mathrm{mL})$. The highest IAA production was observed in the B. aryabhattai strain DST scab $(146.05 \pm 0.53 \mu \mathrm{g} / \mathrm{mL})$ and the lowest production was observed in the isolate Variovorax boronicumulans strain DST18 $(1.16 \pm 0.23(\mu \mathrm{g} / \mathrm{mL})$.

\subsection{ACC Deaminase Production}

In the genetic screening for the acdS (ACC deaminase synthase) gene, a total of 19 bacterial species were found to be positive, showing sequence similarity to the acdS gene of other bacterial species. An endophytic bacterial strain, specifically the P. fluorescens strain smppsap5, was taken as a positive control. In the plate assay, the B. subtilis strain DST50 was observed to exhibit the highest ACC deaminase activity $(22.61 \pm 0.72 \alpha-$ ketobutyrate $\mu \mathrm{M} / \mathrm{g} / \mathrm{h})$, followed by the B. amyloliquefaciens strain DST scab4 (19.31 \pm 0.72 $\alpha$-ketobutyrate $\mu \mathrm{M} / \mathrm{g} / \mathrm{h}$ ), and the lowest activity was exhibited by the Povalibacter uvarum strain DST24 (6.41 $\pm 1.02 \alpha$-ketobutyrate $\mu \mathrm{M} / \mathrm{g} / \mathrm{h})$ (Table 1$)$.

\subsection{Biological Nitrogen Fixation}

All the isolates were screened for the nifH gene and four strains, namely the B. subtilis strain DST10, Klebsiella pneumoniae strain DST36, B. velezensis strain DST42, and Micrococcus yunnanensis strain DST70, were found to be positive, showing sequence similarity to the nifH gene of other bacterial species. A total of 13 isolates, namely the $B$. 
velezensis strain DST scab7, B. aryabhattai strain DST Scab9, B. subtilis strain DST10, P. veronii strain DST21, B. foraminis strain DST26, P. psychrophila strain DST28, P. fragi strain DST29, Paenibacillus lautus strain DST31, B. subterraneus strain DST33, K. pneumoniae strain DST36, B. velezensis strain DST42, P. libanensis strain DST64, and M. yunnanensis strain DST70), were positive for nitrogen fixation.

\subsection{Phosphate Solubilization}

All the isolated bacterial endophytes were screened for phosphate solubilization ability and it was observed that only 14 isolates released phosphate from tri-calcium phosphate (Table 1). Additionally, it was observed that quantitative solubilization varied from 102. $16 \pm 1.05(\mu \mathrm{g} / \mathrm{mL})$ to $225.51 \pm 1.01(\mu \mathrm{g} / \mathrm{mL})$ in the O. anthropi strain DST61 and P. fluorescens strain DST22, respectively, while the solubilization index varied from 1. $34 \pm 0.18$ in the P.libanensis strain DST64 to 2. $53 \pm 0.01$ in the Pseudomonas fragi strain DST29, and was statistically at par with the P. veronii strain DST21 and P. peoriae strain DST32 with the solubilization indexes of $2.52 \pm 0.09$ and $2.52 \pm 0.19$, respectively.

\subsection{Qualitative Estimation of Siderophore Production, Ammonia Secretion, and Hydrogen Cyanide Production}

All the isolated bacterial endophytic strains were screened for $\mathrm{NH}_{3}$ production, $\mathrm{N}_{2}$ fixation, siderophore production, and HCN production, and it was observed that among all the isolated strains, a total of 20,13,16, and 11 isolates were observed to be positive for $\mathrm{NH}_{3}$ production, $\mathrm{N}_{2}$ fixation, siderophore production, and $\mathrm{HCN}$ production traits, respectively. A multivariate analysis (principal component analysis (PCA)) was used as a tool to gain insight into the complexity of the bacterial microflora so as to analyze the outputs of each. The results of the qualitative screening indices were converted to binary codes ( 1 , isolate positive to the test; 0 , isolate negative to the test) to run the PCA (Table 2). The number of microbial groups was confirmed by the cluster analysis approach and this resulted in the formation of 12 clusters (Figure 5) based on similarity indices.

Table 2. Output for the PCA of the qualitative plant growth-promoting attributes pertaining to isolated endophytic bacterial microflora.

\begin{tabular}{|c|c|c|c|c|c|}
\hline Bacterial Strains & CL & $\mathbf{N}$ & AN & CN & $\mathbf{S}$ \\
\hline NWHA-18, NWHA-65 & A & 0 & 0 & 1 & 0 \\
\hline NWHA-4, NWHA-24, NWHA-39 & $\mathrm{B}$ & 0 & 0 & 1 & 1 \\
\hline NWHA-7, NWHA-1 & $\mathrm{C}$ & 1 & 1 & 1 & 1 \\
\hline NWHA-28, NWHA-29 & $\mathrm{D}$ & 1 & 0 & 1 & 1 \\
\hline $\begin{array}{l}\text { NWHA-8, NWHA-2, NWHA-3, NWHA-11, } \\
\text { NWHA-12, NWHA-13, NWHA-15, NWHA-17, } \\
\text { NWHA-19, NWHA-20, NWHA-25, NWHA-37, } \\
\text { NWHA-38, NWHA-40, NWHA-41, NWHA-43, }\end{array}$ & & & & & \\
\hline $\begin{array}{l}\text { NWHA-44, NWHA-45, NWHA-50, NWHA-51, } \\
\text { NWHA-52, NWHA-54, NWHA-55, NWHA-56, } \\
\text { NWHA-57, NWHA-58, NWHA-59, NWHA-61, } \\
\text { NWHA-62, NWHA-63, NWHA-66, NWHA-68, } \\
\text { NWHA-69 }\end{array}$ & $\mathrm{E}$ & 0 & 0 & 0 & 0 \\
\hline NWHA-32, NWHA-42 & $\mathrm{F}$ & 1 & 1 & 0 & 0 \\
\hline NWHA-14, NWHA-34 & G & 0 & 1 & 1 & 0 \\
\hline $\begin{array}{c}\text { NWHA-30, NWHA-5, NWHA-22, NWHA-23, } \\
\text { NWHA-27, NWHA-35, NWHA-46, NWHA-48, } \\
\text { NWHA-49, NWHA-67 }\end{array}$ & $\mathrm{H}$ & 0 & 1 & 0 & 0 \\
\hline NWHA-10, NWHA-33, NWHA-36 & I & 1 & 0 & 0 & 1 \\
\hline $\begin{array}{l}\text { NWHA-9, NWHA-21, NWHA-26, NWHA-31, } \\
\text { NWHA-64, NWHA-70, }\end{array}$ & $\mathrm{J}$ & 1 & 0 & 0 & 0 \\
\hline NWHA-53, NWHA-71, & $\mathrm{K}$ & 0 & 0 & 0 & 1 \\
\hline NWHA-6, NWHA-16, NWHA-47, NWHA-60 & $\mathrm{L}$ & 0 & 1 & 0 & 1 \\
\hline
\end{tabular}




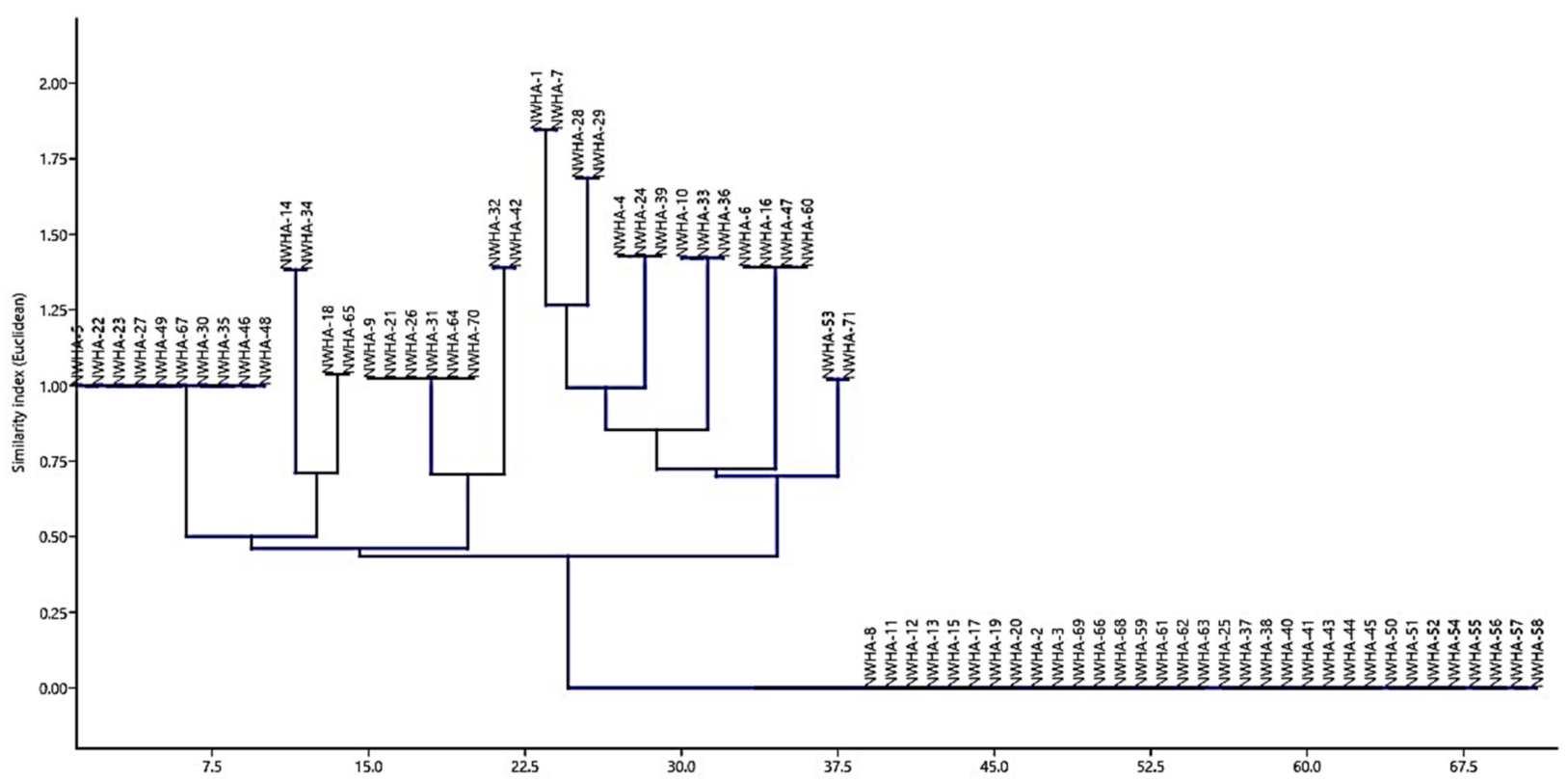

Figure 5. Cluster diagram based on the similarity index (Euclidian) in the context of the various functional traits $\left(\mathrm{NH}_{3}\right.$ production, $\mathrm{N}_{2}$ fixation, siderophore production, and $\mathrm{HCN}$ production) pertaining to isolated bacterial microfloral endosymbiosiomes of apple. The microflora with homogeneity in the functional attributes were clubbed, as shown in the diagram.

The output of such an analysis (cluster and PCA analysis) contains two parts: strain distribution in the factorial space and the table of all the isolates included in different groups (A to L). Figure 6 displays variable and case distribution for isolated microflora; the analysis accounted for $57.621 \%$ of the total variance. The first factor (with 1.303 eigenvalue) was positively related to $\mathrm{NH}_{3}$ production and siderophore production (loadings of 0.523 and 0.805 , respectively), while the second factor (with 1.028 eigenvalue) was related to $\mathrm{N}_{2}$ fixation and HCN production, with positive (0.717) and negative loadings (0.00-0.717). A total of 12 phenotypic groups were formed by the isolated microflora on the basis of the qualitative traits. The isolates in group $\mathrm{C}$ were all positive to the qualitative traits (Bacillus sp.) and group E (33 strains) included bacterial isolates negative to all the traits, and these groups clustered in the bi-plot as per the homogeneity with respect to the qualitative traits. The PCA (Figure 6) suggested a high level of biodiversity and complexity within the isolated microflora in the context of the traits discussed. Thus, this provides a clear representation regarding which traits in the microflora move in a similar direction and hence offers insights into the complexity of the screening process of microflora (most of the fungistatic strains were negative to these qualitative traits). 


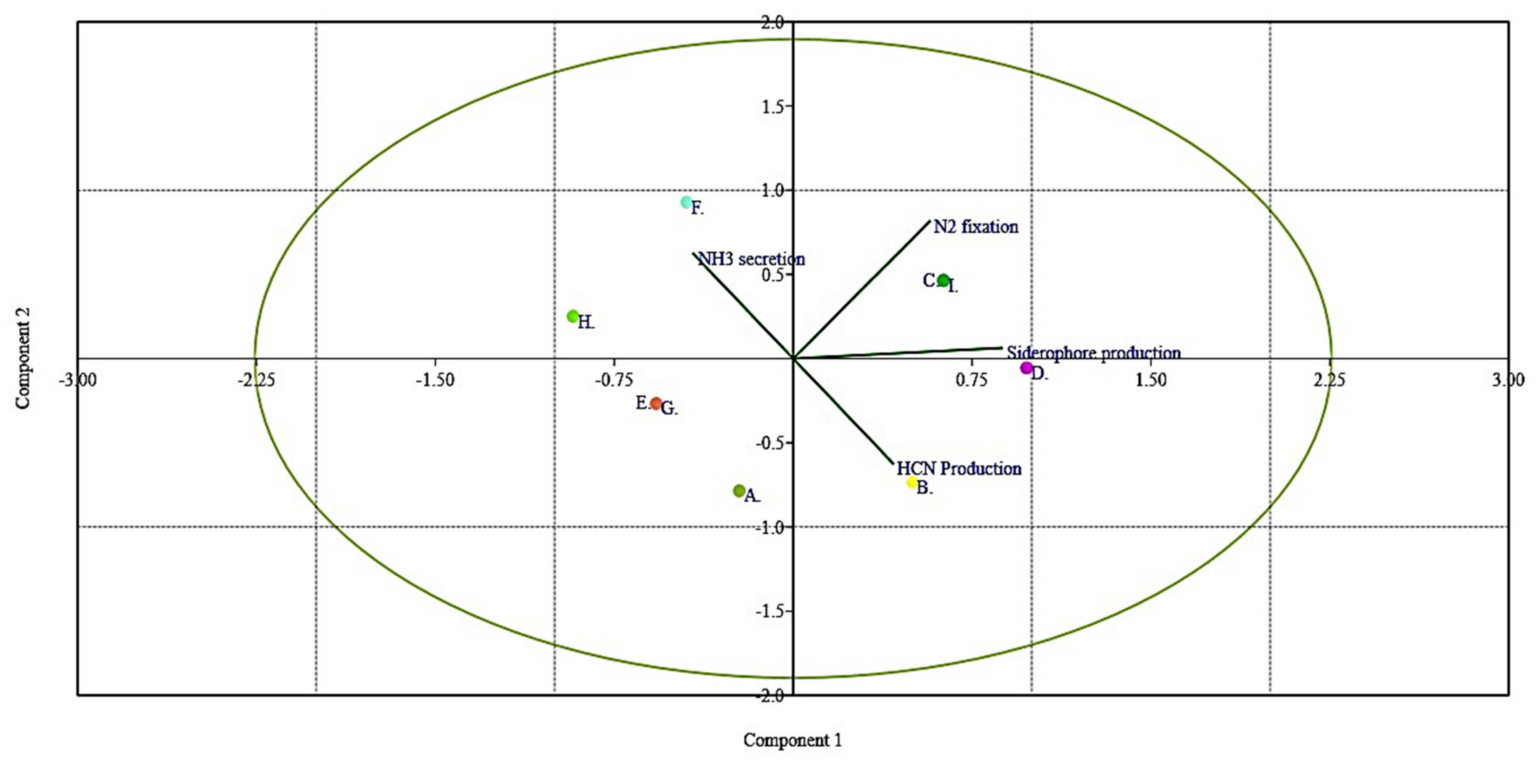

Figure 6. Principal component analysis (PCA) based on the qualitative assessment of $\mathrm{NH}_{3}$ production, $\mathrm{N}_{2}$ fixation, siderophore production, and HCN production (represented by the navigating lines) pertaining to isolated fungistatic bacterial microflora against Venturia inqualis of the apple germplasm. The PCA of the qualitative metabolite production revealed that principal component 1 (PC1) and principal component 2 (PC2) accounted for 38.733\% and 29.572\% of the data variation, respectively. Letters in the figure represent the different clusters generated in the cluster analysis.

\subsection{Effect of Isolated Cultures on the Disease Incidence and Severity on Leaves under Pot House Conditions}

The top isolates showing the highest percentage growth inhibition of $V$. inaequalis, which included the B. aryabhattai strain DST scab, B. amyloliquefaciens strain DST scab4, B. velezensis strain DST scab7, P. xylanexedens strain DST14, Rahnella aquatilis strain DST15, P. psychrophila strain DST28, P. fragi strain DST29, B. subterraneus strain DST33, K. pneumoniae strain DST36, and Leclercia adecarboxylata strain DST39, were selected for formulation development. The isolates were found to be compatible with each other when grown as a consortium and these isolates had huge variation with respect to different molecular and biochemical attributes (Tables 3 and 4). Then, these isolates were grown together to make the formulation. The formulation at all the concentrations caused considerable reductions in both the disease severity and disease incidence in all the tested apple varieties, which included Red Delicious, Gala Redlum, Early Red One, Red Fuji, Gala Mast, Red Chief, and Summer Red. In Red Delicious, the disease intensity was lowest $(44.21 \pm 0.12)$ at $15 \%$ formulation concentration and was statistically similar $(45.09 \pm 0.13)$ with $10 \%$ formulation concentration against the control (98.19 \pm 0.05$)$. In Gala Redlum, the disease intensity was lowest (32.12 \pm 0.21$)$ at $15 \%$ formulation in comparison to the control $(91.95 \pm 0.15)$ and some degree of homogeneity was observed across the apple germplasm tested with minor contradictions (Figure 7). Similarly, the developed endophytic formulation had the significant impact of disease severity. In Red Delicious, the disease severity was lowest $(17.28 \pm 0.24)$ at $15 \%$ formulation concentration, which was statistically at par $(17.33 \pm 0.16)$ with the $10 \%$ formulation concentration against the control (77.56 \pm 0.12$)$. A similar trend appeared for all apple varieties tested with some infinitesimal unconventionalities (Figure 8). 
Table 3. Biochemical and cultural features of formulations forming endophytic microflora.

\begin{tabular}{ccccccccccc}
\hline Attribute & $\mathbf{a}$ & $\mathbf{b}$ & $\mathbf{c}$ & $\mathbf{d}$ & $\mathbf{e}$ & $\mathbf{f}$ & $\mathbf{g}$ & $\mathbf{h}$ & $\mathbf{i}$ & $\mathbf{j}$ \\
\hline 1. & - & - & - & - & - & - & - & - & - & - \\
2. & + & + & + & - & - & + & - & - & - & \\
3. & Rods & Rods & Rods & Rods & Rods & Rods & Rods & Rods & Rods & Rods \\
4. & C & C & C & - & - & - & - & - & - & T \\
5. & - & - & - & - & + & - & + & + & + & - \\
6. & - & - & - & - & + & - & - & - & + & - \\
7. & - & - & - & - & + & - & + & - & - & - \\
8. & + & + & + & + & - & + & + & - & - & + \\
9. & & + & + & + & + & + & - & + & - & + \\
10. & + & + & + & + & + & + & + & + & + & + \\
11. & + & + & + & - & - & - & - & - & - & + \\
12. & + & + & + & + & + & - & + & + & + & - \\
13. & - & + & + & - & - & + & - & - & - & - \\
14. & + & - & - & - & + & + & + & - & + & + \\
15. & + & - & - & - & + & + & + & + & + & + \\
16. & + & + & + & + & + & + & + & + & + & + \\
17. & - & + & + & - & + & + & + & + & + & - \\
18. & - & + & + & - & + & + & + & + & + & + \\
19. & + & + & + & - & - & + & - & - & - & + \\
20. & + & - & - & - & - & + & - & - & - & + \\
21. & + & - & - & - & + & + & + & - & + & + \\
22. & + & + & + & - & - & + & - & - & - & - \\
23. & - & - & - & - & + & - & + & - & + & - \\
24. & - & + & - & - & - & - & - & - & - & - \\
25. & + & + & + & + & + & + & + & + & + & + \\
26. & - & + & - & - & - & + & - & - & - & + \\
27. & - & - & + & - & + & - & + & - & + & + \\
28. & - & - & - & + & + & - & + & + & + & - \\
29. & + & + & - & - & - & + & - & - & - & - \\
30. & + & - & + & + & - & + & - & + & - & + \\
31. & - & - & - & - & - & + & - & - & - & - \\
\hline
\end{tabular}

a: Bacillus aryabhattai strain DST scab; b: Bacillus amyloliquefaciens strain DST scab4; c: Bacillus velezensis strain DST scab7; d: Pseudomonas fragi strain DST29; e: Rahnella aquatilis strain DST15; f: Paenibacillus xylanexedens strain DST14; g: Klebsiella pneumoniae strain DST36; h: Pseudomonas psychrophila strain DST28; i: Leclercia adecarboxylata strain DST39; j: Bacillus subterraneus strain DST33; 1: pigment production; 2: gram reaction; 3: shape; 4: endospore position; 5: indole production; 6: methyl red test; 7: Voges-Proskauer reaction; 8: citrate utilization; 9: oxidase; 10: catalase; $11: \mathrm{H}_{2} \mathrm{~S}$ production; 12: starch hydrolysis; 13: cellulose hydrolysis; 14: acid production; 15: glucose; 16: sucrose; 17: lactose; 18: maltose; 19: amylase; 20: gelatinase; 21: L-arabinose; 22: Lxylose; 23: D-xylose; 24: glutamate decarboxylase; 25: tryptophan deaminase; 26: casein hydrolysis; 27: D-sorbitol; 28: nitrate reduction; 29: lysine decarboxylase; 30: gelatin hydrolysis; and 31: methyl-beta-D-xylopyranoside. $\mathrm{C}=$ central and $\mathrm{T}=$ terminal. 
Table 4. Molecular aspects of isolated microflora based on data retrieved from the National Center for Biotechnology Information, USA.

\begin{tabular}{cccccc}
\hline \multirow{2}{*}{ Strain } & \multicolumn{3}{c}{ Distance Tree Results } & \multicolumn{2}{c}{ Graphics } \\
\cline { 2 - 5 } & Similarity (\%) & E Value & Acc. Len & Max. Score & Total Score \\
\hline DST scab & 99.61 & 0.00 & 1533 & 2832 & 2832 \\
DST scab4 & 100.0 & 0.00 & 1553 & 2868 & 2868 \\
DST scab7 & 99.00 & 0.00 & 1560 & 2881 & 2881 \\
DST scab14 & 99.14 & 0.00 & 1516 & 2819 & 2819 \\
DST scab15 & 99.13 & 0.00 & 1505 & 2780 & 2780 \\
DST scab28 & 99.15 & 0.00 & 1537 & 2839 & 2839 \\
DST scab29 & 99.52 & 0.00 & 1462 & 2693 & 2693 \\
DST scab33 & 99.87 & 0.00 & 1522 & 2811 & 2811 \\
DST scab36 & 99.87 & 0.00 & 1498 & 2767 & 2767 \\
DST scab39 & 9.93 & 0.00 & 1449 & 2676 & 2676 \\
\hline
\end{tabular}
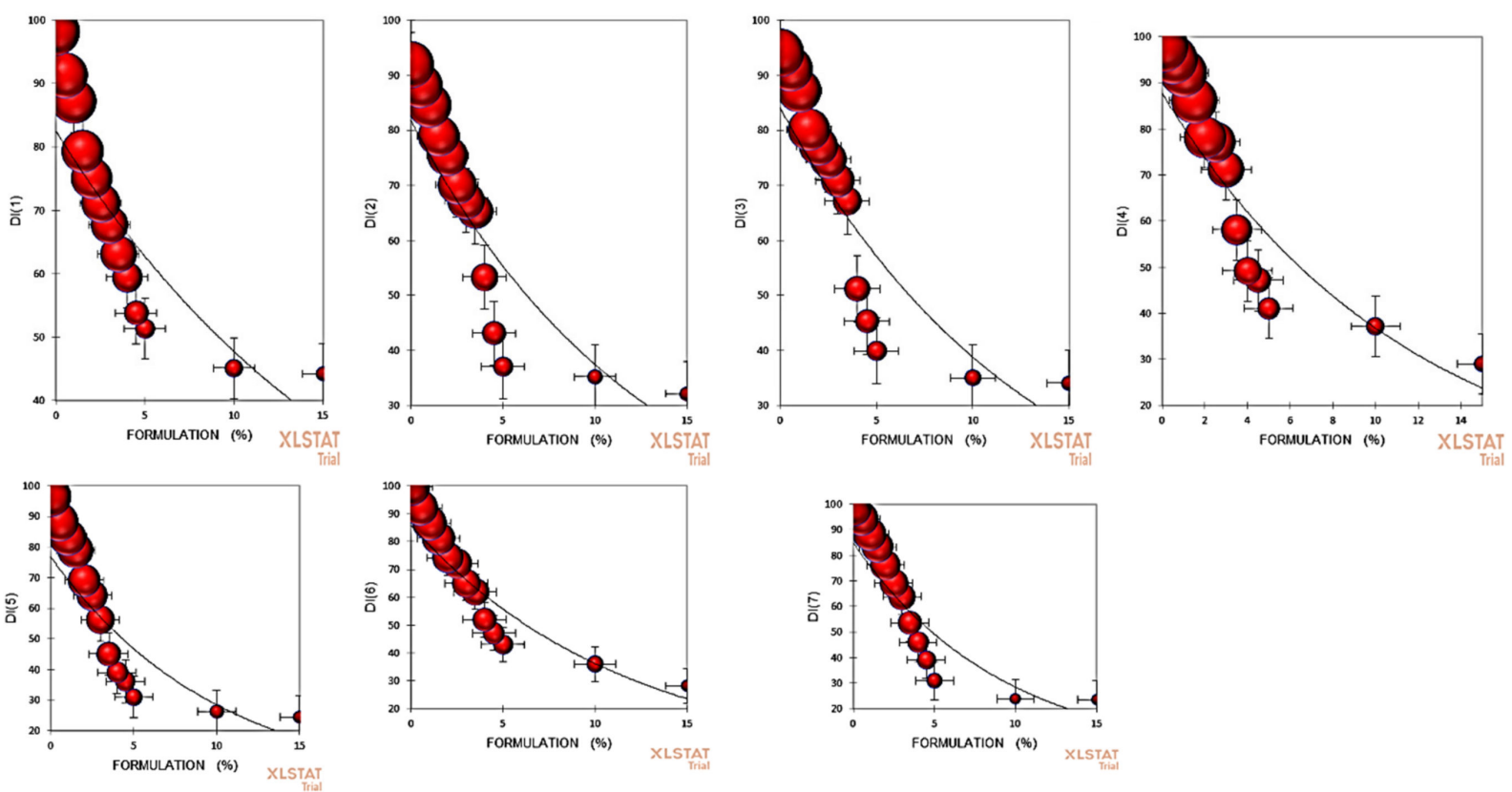

Figure 7. In the scatter plot, DI (1) represents the disease incidence in Red Delicious; DI (2) represents the disease incidence in Gala Redlum; DI (3) represents the disease incidence in Early Red One; DI (4) represents the disease incidence in Red Fuji; DI (5) represents the disease incidence in Gala Mast; DI (6) represents the disease incidence in Red Chief; and DI (7) represents the disease incidence in Summer Red, all vs. formulation percentage. Balls of different size indicate the disease intensity. 

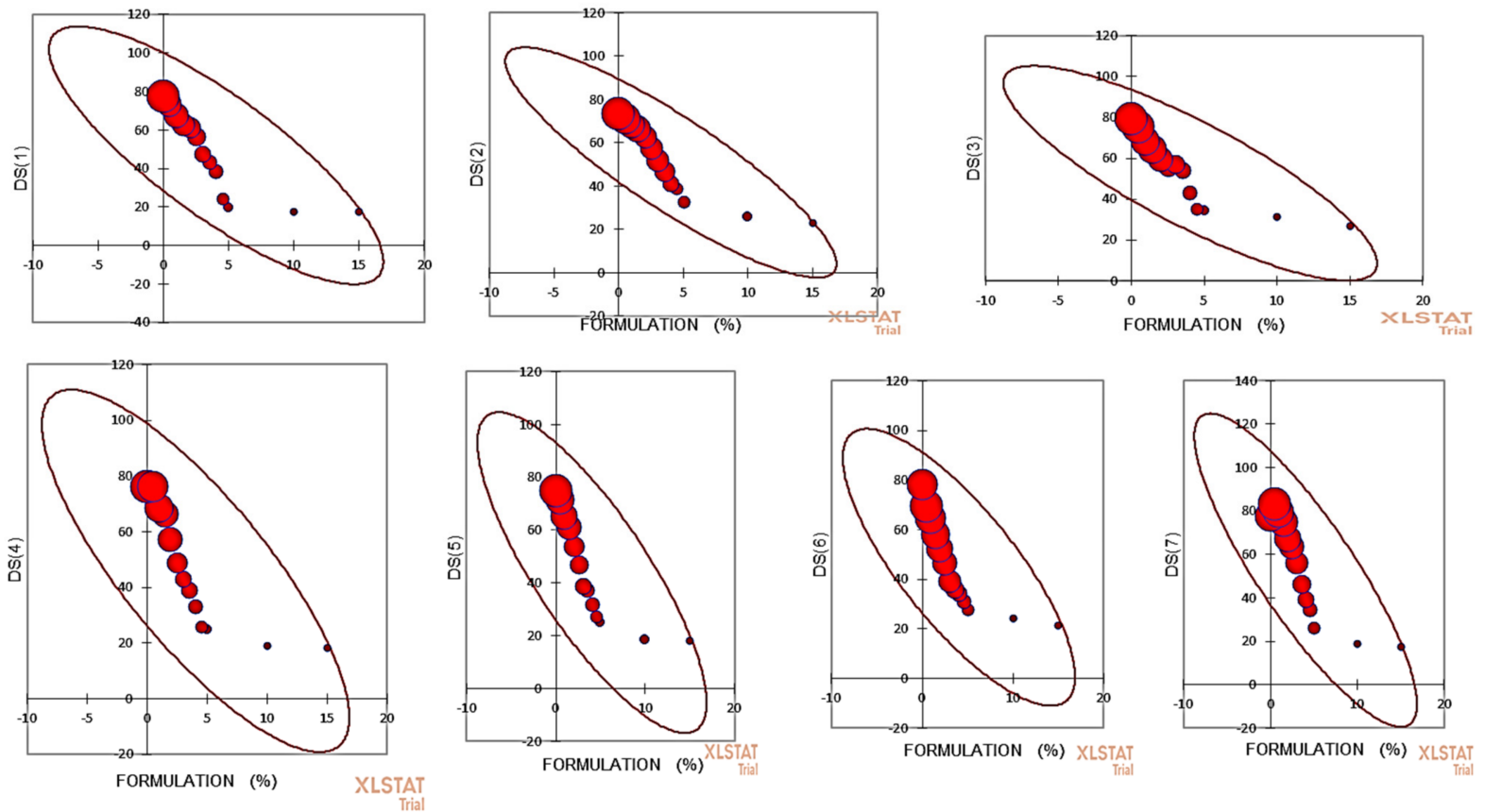

Figure 8. In the scatter plot, DS (1) represents the disease severity in Red Delicious; DS (2) represents the disease severity in Gala Redlum; DS (3) represents the disease severity in Early Red One; DS (4) represents the disease severity in Red Fuji; DS (5) represents the disease severity in Gala Mast; DS (6) represents the disease severity in Red Chief; and DS (7) represents the disease severity in Summer Red, all vs. formulation percentage. Balls of different size indicate the disease severity.

\subsection{Biochemical Alterations Post Endophyte Inoculation}

Investigated cultivar Red Delicious, being the most important cultivar of the Kashmir valley, revealed different levels of enzyme production, chlorophyll, and sugars upon inoculation with the bacterial formulation against the non-inoculated control (Figure 9. The peroxidase (GPOD) content was observed to be 8.82 (A470/min g FW) in 15\% formulation concentration against the control [18.19 (A470/min g FW)]. Furthermore, superoxide dismutase (SOD), catalase (CAT), acid phosphatase (ACP), ascorbic acid peroxidase (POD), and Esterase (EST) content varied largely upon inoculation with the formulation (Figure 10). Glucose content was observed to be highest $(774.09 \mu \mathrm{g} / \mathrm{g} \mathrm{FW})$ at $15 \%$ formulation concentration and lowest in the untreated control $(349 \mu \mathrm{g} / \mathrm{g} \mathrm{FW})$. A similar trend was seen in the fructose content, while the chlorophyll content was observed to be highest $(2.31 \mathrm{mg} / \mathrm{g} \mathrm{FW})$ in the plants treated with the $15 \%$ formulation concentration and lowest in the untreated control $(1.27 \mathrm{mg} / \mathrm{g} \mathrm{FW})$, and chlorophyll $\mathrm{b}$ varied in a similar fashion. Correlation studies on these parameters revealed that there was a significant correlation observed with different magnitudes of coefficients, as represented by the correlation matrix (Pearson) and by coefficients of determination (Figure 10). 

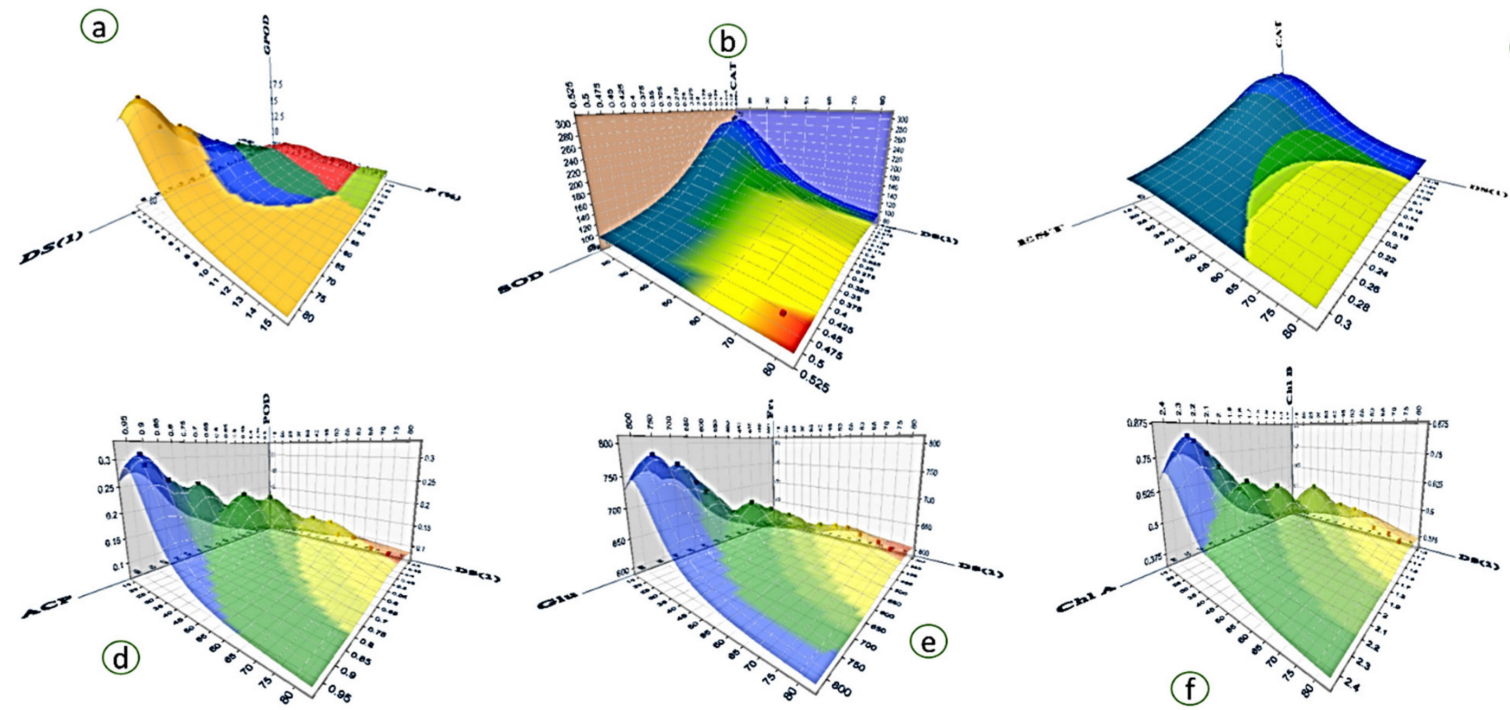

(c)

Figure 9. Plot representing potent endophyte formulation impact on the Red Delicious variety of apple: (a) disease severity and GPOD activity as influenced by formulation percentage; (b) effect on CAT and SOD; (c) effect on CAT and EST; (d) effect on POD and ACP; (e) effect on glucose and fructose; and (f) effect on Chlorophyll a and Chlorophyll b. The biochemical response was recorded in the apple leaves. The abbreviations indicate: peroxidase (GPOD), catalase (CAT), superoxide dismutase (SOD), ascorbic acid peroxidase (POD), esterase (EST), and acid phosphatase (ACP).
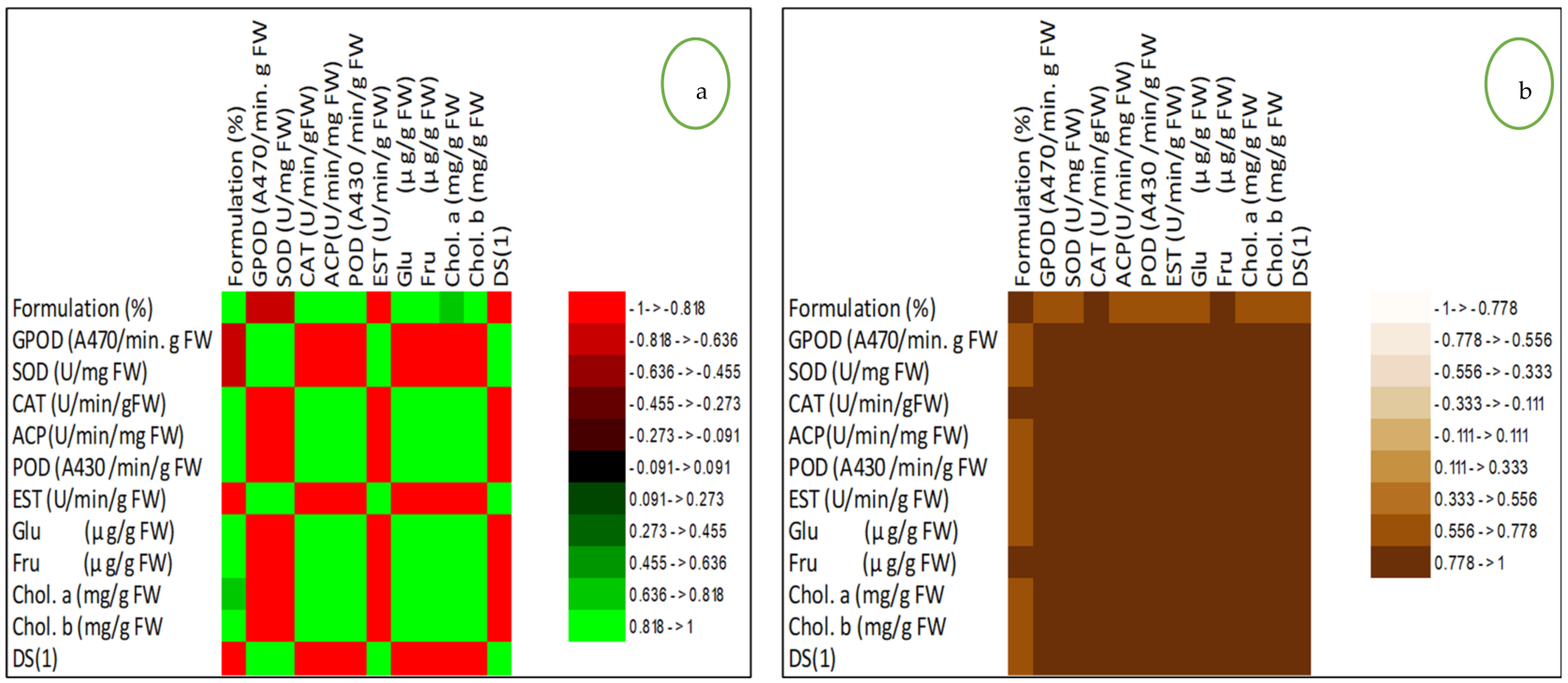

Figure 10. (a): Correlation matrix (Pearson) and (b): Coefficients of determination (Pearson) of disease severity (DS1), formulation percentage and physiological attributes. Abbrevations indicate: peroxidase (GPOD), catalase (CAT), superoxide dismutase (SOD), ascorbic acid peroxidase (POD), esterase (EST), acid phosphatase (ACP)] in Red Delicious apple variety. The biochemical response was recorded in the apple leaves.

In order to have a better understanding of the relationship between the formulation concentration and the biochemical response, which was not identified by the correlation analysis, and to determine the influence of each variable, principal component analysis (PCA) was applied (Figure 11). The eigenvalue of principal component 1 and principal component 2 were greater than 1 (Figure 11a) and thus were considered for the PCA. The PCA of GPOD, CAT, SOD, POD, EST, ACP, DS1, chlorophyll, glucose, and fructose with respect to different formulation concentrations $(C)$ in Red Delicious revealed that principal component 1 (F1) and principal component 2 (F2) accounted for $97.08 \%$ and $1.68 \%$ of the data variance, respectively, as shown in biplot and Bootstrap ellipses (Figure 11). The first 
factor was related to acid phosphatase (represented by ACP in the biplot), ascorbic acid peroxidase (POD), glucose (Glu), fructose (Fru), chlorophyll a (Chl.A), disease severity (DS1), and Chlorophyll b (Chl.B), with loadings of 0.718, 0.720, 0.608, 0.657, 0.710, 0.752, and 0.719 , respectively. The second factor was related to peroxidase (GPOD), superoxide dismutase (SOD), catalase (CAT), and esterase (EST), with loadings of $0.674,0.587,0.623$, and 0.522 , respectively. The principal component scores on PC1 had the same sign between the disease severity and formulation concentrations up to the formulation concentration magnitude of $3 \%$ and then changed to opposite signs beyond this concentration, depicting the prominent effect of formulation concentration beyond this level. The overlapping scores of the last two concentrations (concentration of $10 \%$ and $15 \%$ ) revealed the peak effect values of formulation (Figure 11b, bootstrap ellipses). As there was huge variation in the data due to heterogeneity in the measurement scales, the data was normalized by Z-score normalization.
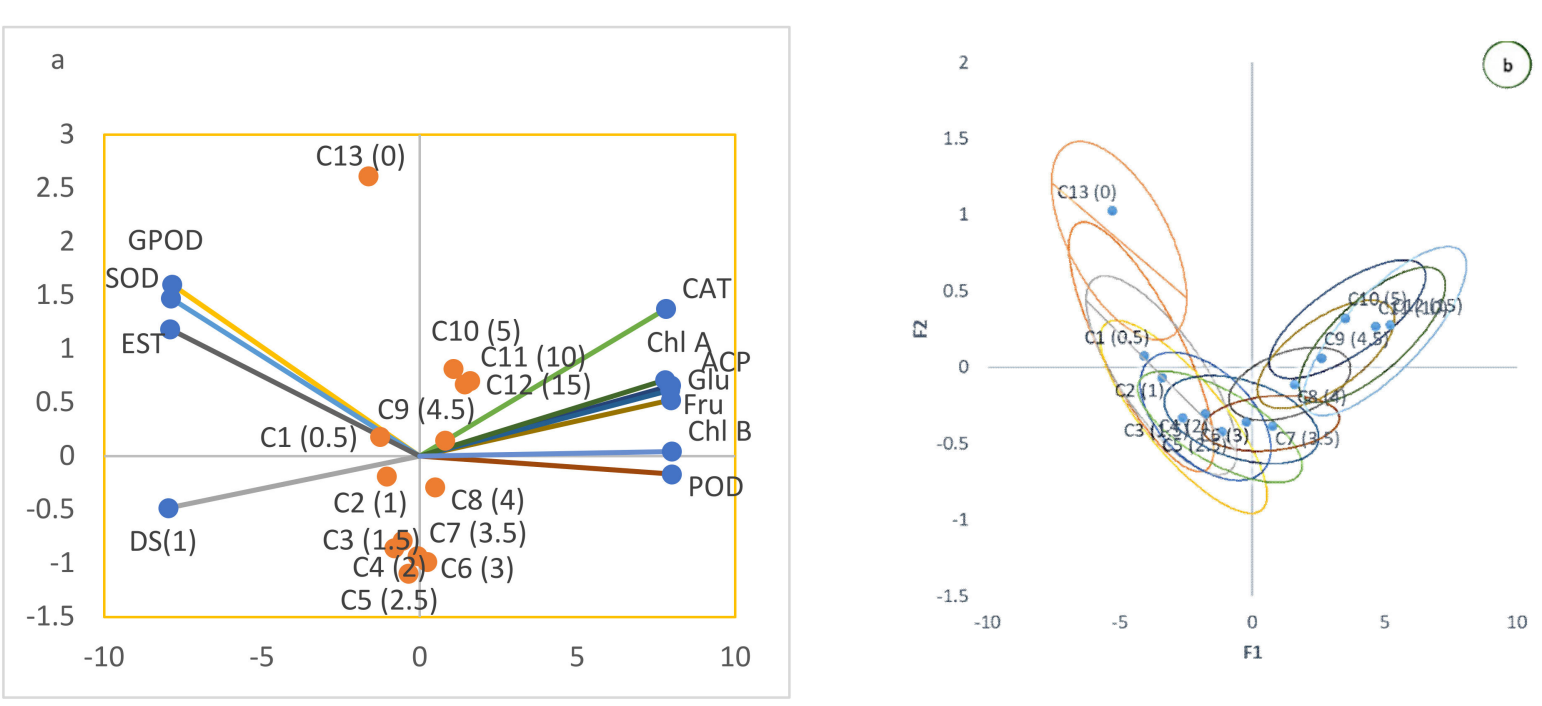

Figure 11. Principal component analysis (PCA) of disease severity (DS1) and various defense enzymes; peroxidase (GPOD), catalase (CAT), superoxide dismutase (SOD), ascorbic acid peroxidase (POD), esterase (EST), and acid phosphatase (ACP). Disease severity (DS1), chlorophyll, glucose, and fructose with respect to different formulation concentrations are represented by solid colored dots in A and C in b. The PCA of the defense response to bacterial formulation in Red Delicious revealed that principal component 1 (F1) and principal component 2 (F2) accounted for $97.28 \%$ and $1.739 \%$ of the data variance, respectively. The first graph (a) represents the biplot of the axes in which different variables are represented by different colored axes and the second graph $(\mathbf{b})$ represents the bootstrap ellipses in which concentrations of the formulation are represented by $\mathrm{C}$ and their corresponding value is given in brackets.

\section{Discussion}

$V$. inaequalis, which causes apple scab, is economically the most important pathogen in apple-based farming systems worldwide. Scabs are considered to be the most important disease in apple in terms of yield loss, which can reach as much as 70\% [16]. The chemical-based management strategies currently employed across the globe have raised public concerns over pesticide residue in foods, thereby generated a great deal of interest in reducing their use. The present management strategies have resulted into ecological degradation and economically burdens farming communities. Therefore, some economically realistic and biological-by-origin strategies need to be developed for the proficient management of this disease to thereby reduce the health hazards of pesticides on the consumer. Bacterial endophytes are one of the most significant non-pathogenic entities concomitant with plants across the family lines. Besides being the prominent candidate of endosymbiosiome, bacterial endophytes have the potential to attract the most interest among almost all the biological phytopathogen management strategies in changing the global climate scenario. These aspects have made this strategy one of the low cost and 
ecologically sound tools in the integrated crop disease clampdown. As they are native candidates to plant niches, they are known for not disturbing the existing microfloral equilibrium. They are also extremely versatile in metabolism, which has made them the most interesting entity to researchers across the world. Therefore, their antifungal behavior as well as the presence of various genes and metabolites as a central mechanism to their mode of action have been investigated in this research study. A total of 150 strains isolated from various apple varieties were studied in this investigation, collected across the apple germplasm centers of Jammu and Kashmir, India. However, we limited our study to only 71 isolates based on their capability to inhibit the growth of $V$. inaequalis in vitro, expressed as a percentage growth inhibition that varied from $96.35 \pm 0.03 \%$ to $11.25 \pm 0.08 \%$. The inhibitory activity of bacterial endophytes against $V$. inaequalis in the present study was much more advanced than as previously reported $[14,15]$. In the screening process, we found that the highest number of fungistatic bacterial strains were isolated from Golden Delicious germplasm, followed by Fenna, and lowest number derived from the variety Fuji Zehn Aztech and Gala Mast, thus giving an indication to the existence of heterogeneity among the sampled cultivars in the context of scab resistance. The extent of endophyte colonization in plants by endophytes was observed to be correlated to disease resistance [33]. Liu et al., [41] reported that the endophyte community-shaping in apple is being determined by the type of tissue, the sampling site, and cultivar, which in turn have a prominent impact on the number of potential antifungal biota strains present. The plant endosymbiosiomes have been widely used to isolate microflora with biocontrol ability [42] and the studies on such entities have revealed their abilities to contribute in conferring resistance to crops against various phytopathogens, including other substantial benefits on the host such as nutrient acquisition, enhanced growth, and improved resistance to heat, drought, and other stresses [43]. The present study revealed that there is an abundant diversity of bacterial microflora across the Himalayan apple germplasm with respect to their antifungal behavior against $V$. inaequalis. Among the isolated fungistatic microflora, the endophytes of the family Gracilicutes were found to be abundant in numbers, totaling to $45.15 \%$ of the total isolates. Based on the $16 \mathrm{~S}$ rRNA gene sequences of the isolated bacterial endophytes prominently belonging to the Bacillus, Pseudomonas, Enterobacter, and Paenibacillus genus, the endophytic lifestyle of these genus have been widely reported in many crops $[44,45]$. The apple plant has been widely observed to niche the endophytes that have huge potential to contain the pathogenic fungal growth and their relative proportion is dependent on the type of cultivar and plant part selected for sampling [46]. Although the present investigation revealed the denser proportion of fungistatic bacterial microbiota in comparison to previous reports, which could be attributed to the more diverse apple germplasm of the Himalayan foot hills of India that were selected for the isolation of the investigated bacterial endophyte strains, among the pooled isolated microbiota, a total of $59.15 \%$ of the bacteria were observed to be gram-negative and $40.85 \%$ to be gram-positive. Zhang et al., [47] reported the predominance of gram-negative bacteria among the plant tissues, although some researchers reported contrary results to our findings [48]. The bacterial microflora in different scab-infested plant parts resulted in the changed genetic and physiological behavior; therefore, the characteristics of diversity and the physiology of the pooled fungistatic microbiota could help us to understand their ability to ameliorate the success of the host against diseases. In the present investigation, all the collected microflora were visualized and in this context, the diversity indices, namely the Simpson index, Shannon index, Margalef index, and other indices, varied greatly. Studies on the putative hyper-diversity indices regarding endophytes in all major linages of terrestrial plants have revealed fluctuating results on all the major diversity indices [49], wherein the abundance, diversity, richness, and communities may largely be influenced by the habitat of the plantations [50], thereby validating our findings on the investigated facet of diversity. The population of bacterial endophytes in the sampled tissues varied from $\log _{10} 4.70 \times 10^{5}$ to $\log _{10} 8.27 \times 10^{5}(\mathrm{cfu} / \mathrm{gFW})$, which agrees with the population ranges in previous studies of endophytic bacteria in many crops [51,52]. The variation in the bac- 
terial endophytic populations experienced robust fluctuations that prevalently depended upon factors including the type of germplasm screened, the physiological transitions, the dynamics among the host plants, and the soil environment attributes such as nutrient dynamics, organic matter fluctuations, plant genetic constitution, tissue type, and plant ecology [53].

All the isolates were subjected to the determination of their plant growth-promoting abilities and it was found that the culture supernatant of 32 isolates produced IAA, which varied from $1.16 \pm 0.23(\mu \mathrm{g} / \mathrm{mL})$ to $146.05 \pm 0.53(\mu \mathrm{g} / \mathrm{mL})$. Our findings are in agreement with many researchers [54,55]. In our study, an impressive number of strains (19) were positive to the existence of the acdS gene and a majority among them were Firmicutes but only nine were seen to produce ACC deaminase in liquid assay; one of the possible reasons for this could concern the absence of some important inducers that are needed for acdS expression. Among the nine strains, the B. subtilis strain DST50 exhibited the highest ACC deaminase activity $(22.61 \pm 0.72 \mu \mathrm{M} / \mathrm{g} / \mathrm{h})$ and the Povalibacter uvarum strain DST24 $(6.4 \pm 1.02 \mu \mathrm{M} / \mathrm{g} / \mathrm{h})$ exhibited the lowest activity in this context. The activity reported in the current investigation is considerably higher than previously reported B. subtilis strains [56], which were only $448.3 \pm 2.91 \mathrm{nM} \alpha$-ketobutyrate $/ \mathrm{mg} / \mathrm{min}$. In a similar fashion, all the isolates were screened for the nitrogen-fixing attribute and a total of 13 isolates were observed to be positive for nitrogen fixation, but the sceening for the presence of the nifH gene revealed that only four strains (B. subtilis strain DST10, K. pneumoniae strain DST36, B. velezensis strain DST42, and M. yunnanensis strain DST70) were found to be positive, showing sequence similarity of the nifH gene to other bacterial species [57]. The detection in the other strains could not be made even after using degenerate primers from the known nifH gene and this could be possibly attributed to the high divergence in nifH gene sequences. The thirteen strains were seen to utilize the atmosphere-embedded nitrogen and remarkably, seven of them were isolated from the shoot (leaves and twigs). Some bacterial endophytic microflora from the stem and leaves have been investigated for effective nitrogen fixation $[58,59]$ and interestingly, these shoot-associated endophytic microflora had the advantage over their root bacteria counterparts as they inhabited the less competition-based aerial niche for nitrogen fixation and growth [59].

In the present investigation, the $P$. fluorescens strain DST22 showed maximum phosphate solubilizing ability, which was $225.51 \pm 1.01(\mu \mathrm{g} \mathrm{P} / \mathrm{mL})$, and the solubilization index was highest in the P. fragi strain DST29 $(2.53 \pm 0.01)$. Although many strains of $P$. fluorescens have been observed to solubilize phosphate [60], in the present study, P. fluorescens showed far higher phosphate solubilization and a far higher solubilization index than earlier reported strains such as the P. fluorescens strain PMS1 [61]. Bacterial endophytes play a pivotal role in plant development in controlling the phosphorus availabilities [62]. The release of copious acids (organic) such as gluconic acid results in the acidification of soils and causes phosphate solubilization from various sources in the soil solution. Gluconic acid has been found to convert inorganic phosphate into ortho-phosphorus acid, which is the available form to be taken up by the plants. In the qualitative detection of some important plant growth-promoting traits among the isolated bacterial endophytes, a total of 16 strains produced siderophores and ammonia was produced by a total of 20 isolates, while hydrogen cyanide was produced by a total of 11 isolates. It was also reported that there is siderophore production among the bacterial isolates in a similar range [62]. Other researchers have also widely documented the siderophore production process of bacterial endophytes [63]. In the present investigation, the studied bacterial endophytic strains could prevent phytopathogens from obtaining an adequate quantity of iron due to their ability to produce siderophores, therefore limiting their capability to thrive and multiply. This mechanism of induced iron starvation can be the possible reason for their antifungal behavior. The iron chelation through this mechanism does not impact the plant development as plants grow at significantly poorer iron echelons than the invading pathogenic microflora [64]. Even in certain cases, plants can take up the bacteria-oriented iron-siderophore complexes jointly [65]. Hydrocyanic acid, a volatile metabolite produced by various microbes, is well 
known for its role against various pathogens and thus plays a vital role in the biological control of phytopathogenesis [66]. Bacterial endophytes capable of producing hydrocyanic acid have been widely reported by many researchers [67].

Kaspar et al., while carrying out the isolation of endophytic bacterial isolates from Amaranthus hybridus, Solanum lycopersicum, and Cucurbita maxima, evaluated them for hydrocyanic acid production and observed similar findings as in the present investigation [56]. Ammonia can be secreted by microbes through numerous routes such as through nitrite ammonification, metabolism of some amino acids, and production of biogenic amines, and can be secreted also ammonia through amino acid decarboxylation deamination and urea degradation (hydrolytic) mediated by urease [68]. Most of these processes occur among soil microflora but, similar to our findings, many researchers have found endophytic bacteria such as Bacillus sp., Pseudomomas sp., and Klebsiella sp. growing endophytically and supplying ammonia to plant hosts so as to meet its nitrogen requirements [69]. The utility of the PCA concerns a reduction in the number of observations and concerns converting them into factors that contribute to variation; thus, in order to see the homogeneity among the isolates in this context to qualitatively study traits, the PCA helped us to determine the clustering of taxonomic groups, thus allowing us to draw relationships between the isolated microbiota in the context of traits importance. The PCA suggested a high level of biodiversity and complexity within the isolated microflora in the context of the $\mathrm{N}$-fixation, ammonia secretion, HCN production, and siderophore production. Thus, this provides insight regarding the fact that most of the fungistatic strains were negative to these qualitative traits, therefore the possible mode of action in the fungistatic microflora could be the combination of them together. The PCA on all these traits also explained the niche-based role of the endophytic microflora, as explained by many investigators earlier [70,71]

The formulation used in this investigation inhibited the scab significantly at all the tested concentrations. The disease incidence and severity as a suppression measure was significantly reduced by the formulation used at higher concentrations and in certain cases, the lower concentrations were as good as the control. In our study, the results on the disease suppression suggest that endophytic bacteria can largely be tested to act as profound tools in phytopathogen management, which is in line with the $100 \%$ of diseases' containment with bacterial endophytic cell-free supernatants as reported by several investigators across the globe [72]. The antifungal behavior of endophytic bacteria could be attributed to the biosynthesis of numerous allelo-chemicals [73]. The impact on the disease severity and disease incidence at all the concentrations could be the result of the presence of some antimicrobial compounds such as phenazines, ammonia, pyrrolnitrin, hydrocyanic acid, and pyoluterorin [74]. In Pseudomonas sp. and similarly in B. subtilis strain E1R-j, endophytic microflora from wheat (roots) revealed high fungistatic activity and thereby reduced the disease intensity $(90.97 \%)$ under pot house conditions [75]. The endophytic microfloral formulations have been reported to exhibit higher blight disease containment. The mechanism employed by biological control tools to antagonize and check both the phytopathogen proliferation and advancement can be separated into four classes, namely the induction of plant defense through SAR (systemic-acquired resistance), competition, antibiosis, and finally parasitism [73]. Antibiosis largely refers to antimicrobial compounds and a huge number of antimicrobial compounds such as 2,4diacetylphloroglucinol (DAPG), oomycin A, phenazine, tropolone, pyoluterorin, hydrogen cyanide, pyrrolnitrin, tensin, amphisinand, and cyclic lipopeptides were produced by pseudomonads [64], while xanthobaccin, oligomycin A, zwittermicin A, and kanosamine were produced by Streptomyces sp., Stenotrophomonas sp., and Bacillus sp. [74]. The wilt prevalence in eggplant to an extent of more than $70 \%$ was reported to be contained by the formulations of Pseudomonas sp., Enterobacter sp., and Bacillus sp., and it was found that most of these isolates produced an antibiotic DAPG under in vitro conditions [75]. The naturally-occurring bacterial endophytes that could confer a prominent disease resistance to plants are very low in number and such populations have to be raised to a specific level in order to encourage a contrasting check in the proliferation of phytopathogens [76]. 
In the present investigation, the cultivar Red Delicious revealed different levels of enzyme production, chlorophyll, and sugars upon inoculation with the bacterial formulation against the non-inoculated control. The peroxidase, superoxide dismutase, catalase, acid phosphatase, ascorbic acid peroxidase, and esterase activity varied significantly in the inoculated plants against the control. Similarly, glucose, fructose, and chlorophyll a and $\mathrm{b}$ content was observed to change drastically upon inoculations against the control. The present investigation is well validated with a preceding report in which microorganisms such as endophytes induce production dynamism across plant metabolites that can ameliorate the tolerance levels to various stresses [76]. In some studies, microorganisms have been found to mediate the interaction between host plants and pathogens by producing antimicrobial compounds and antioxidants, or by inducing systemic resistance [77]. Our findings are supported by the view that endophytes induce the deposition of phenolic compounds and the expression of defense-related enzymes such as peroxidases, catalases, etc. Similar to our findings [17], it was observed that joint formulation of endophytic microflora B. amyloliquefaciens and P. fluorescens amplified plant defense-based enzymes and antioxidants in formulation-treated plants, in contrast to the non-inoculated control. The discrete relationship between the formulation concentration and biochemical response, which was not identified by correlation analysis, was quantified by applying the principal component analysis. The principal component scores on PC1 were moving in the same direction between the disease severity and formulation concentrations, up to the formulation concentration magnitude of $3 \%$, and then changed to opposite signs beyond this concentration, depicting the prominent effect of formulation concentration beyond this level. The overlapping scores of the last two concentrations revealed the peak effect values of formulation, thus giving an indication to optimize the formulation of these overlapping concentrations by maintaining narrow concentration levels in the experimental setup. Concentrations of the formulations have a significant effect on the diseases and therefore need to be optimized cautiously [51]. The colonizing behavior and biochemical response in hosts largely depend upon the formulation concentration [78].

\section{Conclusions}

This investigation confirmed the existence of potential fungistatic bacterial microflora distributed across the plethora of niches in apple germplasm. The isolated potential candidates in the form of bacterial formulation have proved to contain both disease proliferation and damage in all the investigated cultivars of apple, and this could be attributed to the modulated biochemical response in mitigating the stress mediated by the advanced infections of $V$. inaequalis in the host. This investigation provided scientific guidance for the remedies of apple scab through endophyte-mediated biological means. The formulation developed through this investigation needs to be standardized for field-level applications with respect to carrier materials, concentrations, methods of application, environmental dependences, etc., so as to enhance its efficacy. The multi-locational field experiments need to be organized to understand the behavior of these biological entities in different agro-climatic conditions. The future endeavors of this research field should be focused on aspects of transcending or minimizing the molecular and biochemical barriers that are imminent in host-specific plant-microbe interactions during biological disease management execution strategies. For the future prospects, we suggest that the substantial shrinking of the apple scab can be achieved by applying the use of these isolated strains, apart from its uses in the amelioration of plant health and development, under natural environmental conditions. Studies on the identification of their mode of action need to be carried out so as to identify some important key molecules and accordingly their production process may be amplified during their interaction as bioinoculants. The formulation needs to be tested for different application methods and optimized for better efficacy in all possible combinations so as to establish it as a more result-oriented remedy at the field level. 
Supplementary Materials: The following are available online at https: / www.mdpi.com/article/ 10.3390/jof7110923/s1, Table S1: Details of the surveyed apple germplasm and isolation thereof, Table S2: Details of the sequenced microflora with antifungal behavior against Venturia inaequalis.

Author Contributions: Conceptualization, S.A.P.; methodology, S.A.P. and S.M.; software, S.A.P.; validation, S.A.P., S.M. and S.A.B.; formal analysis, S.A.P., S.A.B., S.S., M.A.A. and S.A.P.; investigation, resources, and data curation, S.A.P., O.M.A. and A.N.; writing-original draft preparation and writing-review and editing, S.A.P., D.I.H., S.M.P., S.A.B., S.M.W., T.R.B., H.D. and R.A.R. All authors have read and agreed to the published version of the manuscript.

Funding: This research received no external funding.

Institutional Review Board Statement: Not applicable.

Informed Consent Statement: Not applicable.

Data Availability Statement: Data sharing not applicable to this article.

Acknowledgments: This research study was carried out at the Division of Basic Sciences and Humanities, Division of Plant Pathology, FoH, SKUAST-K, and is highly acknowledged. The funding of this research study was provided by the Department of Science and Technology (SEED Division), Government of India, under the project number SP/YO/121/2017 (G), and is highly acknowledged. The authors would like to extend their sincere appreciation to the Taif University Researchers Supporting Project, number TURSP-2020/262, Taif University, Saudi Arabia.

Conflicts of Interest: The authors declare no conflict of interest.

\section{References}

1. Hanke, M.-V.; Flachowsky, H.; Peil, A.; Emeriewen, O.F. Malus $\times$ Domestica Apple. In Biotechnology of Fruit and Nut Crops; CABI: Wallingford, UK, 2020; Volume 19.3, p. 440.

2. Shah, I.A.; Songara, M. Production and Marketing Problems of Apple Fruit Growers in Jammu and Kashmir: A Critical Study. MANTHAN J. Commer. Manag. 2019, 6, 57-69. [CrossRef]

3. Mansoor, S.; Ahmed, N.; Sharma, V.; Jan, S.; Nabi, S.U.; Mir, J.I.; Mir, M.A.; Masoodi, K.Z. Elucidating genetic variability and population structure in Venturia inaequalis associated with apple scab disease using SSR markers. PLoS ONE 2019, 14, e0224300.

4. Beigh, M.A.; Peer, Q.J.A.; Sibat, F.; Mehraj, S. Resource management for apple scab and sanjose scale control of apple in Kashmir Valley of J\&K State. J. Appl. Nat. Sci. 2015, 7, 447-451.

5. Shafi, S.M.; Sheikh, M.A.; Nabi, S.U.; Mir, M.A.; Ahmad, N.; Mir, J.I.; Raja, W.H.; Rasool, R.; Masoodi, K.Z. An overview of apple scab, its cause and management strategies. EC Microbiol. 2019, 15, 1-4.

6. Chatzidimopoulos, M.; Lioliopoulou, F.; Sotiropoulos, T.; Vellios, E. Efficient control of apple scab with targeted spray applications. Agronomy 2020, 10, 217. [CrossRef]

7. Mansoor, S.; Sharma, V.; Mir, M.A.; Mir, J.I.; Nabi, S.; Ahmed, N.; Alkahtani, J.; Alwahibi, M.S.; Masoodi, K.Z. Quantification of polyphenolic compounds and relative gene expression studies of phenylpropanoid pathway in apple (Malus domestica Borkh) in response to Venturia inaequalis infection. Saudi J. Biol. Sci. 2020, 27, 3397-3404. [CrossRef]

8. Cordero-Limon, L.; Shaw, M.W.; Passey, T.A.; Robinson, J.D.; Xu, X. Cross-resistance between myclobutanil and tebuconazole and the genetic basis of tebuconazole resistance in Venturia inaequalis. Pest Manag. Sci. 2021, 77, 844-850. [CrossRef]

9. Lindsey, A.P.J.; Murugan, S.; Renitta, R.E. Microbial disease management in agriculture: Current status and future prospects. Biocatal. Agric. Biotechnol. 2020, 23, 101468. [CrossRef]

10. Adeniyi, D.O.; Kunwar, D.; Dongo, L.N.; Animasaun, D.A.; Aravind, T. New-Generation Fungicides for Sustainable Production and Disease Suppression. In Emerging Trends in Plant Pathology; Springer: Singapore, 2021; pp. 249-256.

11. Banerjee, R.; Sheoran, S.; Kumar, S.; Sanodiya, R.; Dhanya, V.G.; Samota, M.K. Participatory Rural Appraisal Techniques for Problem Identification and Formulation of Village Agricultural Development Plan of Chosla Village. Asian J. Agric. Ext. Econ. Sociol. 2020, 38, 80-99. [CrossRef]

12. Papp, D.; Gao, L.; Thapa, R.; Olmstead, D.; Khan, A. Field apple scab susceptibility of a diverse Malus germplasm collection identifies potential sources of resistance for apple breeding. CABI Agric. Biosci. 2020, 1, 16. [CrossRef]

13. Guerin, F.; Le Cam, B. Breakdown of the scab resistance gene Vf in apple leads to a founder effect in populations of the fungal pathogen Venturia inaequalis. Phytopathology 2004, 94, 364-369. [CrossRef]

14. Köhl, J.; Scheer, C.; Holb, I.J.; Masny, S.; Molhoek, W.M.L. Toward an integrated use of biological control by Cladosporium cladosporioides H39 in apple scab (Venturia inaequalis) management. Plant Dis. 2015, 99, 535-543. [CrossRef]

15. Fiss, M.; Kucheryava, N.; Schönherr, J.; Kollar, A.; Arnold, G.; Auling, G. Isolation and characterization of epiphytic fungi from the phyllosphere of apple as potential biocontrol agents against apple scab (Venturia inaequalis). Z. Pflanzenkrankh. Pflanzenschutz 2000, 107, 1-11.

16. MacHardy, W.E. Apple Scab: Biology, Epidemiology, and Management; APS Press: St. Paul, MN, USA, 1996. 
17. Mishra, S.; Bhattacharjee, A.; Sharma, S. An Ecological Insight into the Multifaceted World of Plant-Endophyte Association. Crit. Rev. Plant Sci. 2021, 42, 127-146.

18. Kumar, A.; Singh, V.K.; Tripathi, V.; Singh, P.P.; Singh, A.K. Plant growth-promoting rhizobacteria (PGPR): Perspective in agriculture under biotic and abiotic stress. In Crop Improvement through Microbial Biotechnology; Elsevier: Amsterdam, The Netherlands, 2018; pp. 333-342.

19. Sutton, T.B.; Aldwinckle, H.S.; Agnello, A.M.; Walgenbach, J.F. Compendium of Apple and Pear Diseases and Pests; American Phytopath Society: St. Paul, MN, USA, 2014.

20. Coombs, J.T.; Franco, C.M. Isolation and identification of actinobacteria from surface-sterilized wheat roots. Appl. Environ. Microbiol. 2003, 69, 5603-5608. [CrossRef]

21. Lahlali, R.; Bajii, M.; Jijakli, M. Isolation and evaluation of bacteria and fungi as biological control agents against Rhizoctonia solani. Commun. Agric. Appl. Biol. Sci. 2007, 72, 973-982.

22. Kucheryava, N.; Fiss, M.; Auling, G.; Kroppenstedt, R.M. Isolation and characterization of epiphytic bacteria from the phyllosphere of apple, antagonistic in vitro to Venturia inaequalis, the causal agent of apple scab. Syst. Appl. Microbiol. 1999, 22, $472-478$. [CrossRef]

23. Barba, M.; Hadidi, A. An overview of plant pathology and application of next-generation sequencing technologies. $C A B$ Rev. 2015, 10, 1-21. [CrossRef]

24. Pruesse, E.; Quast, C.; Knittel, K.; Fuchs, B.M.; Ludwig, W.; Peplies, J.; Glöckner, F.O. SILVA: A comprehensive online resource for quality checked and aligned ribosomal RNA sequence data compatible with ARB. Nucleic Acids Res. 2007, 35, 7188-7196. [CrossRef]

25. Hanrahan, K.; O’Neill, A.; Prencipe, M.; Bugler, J.; Murphy, L.; Fabre, A.; Puhr, M.; Culig, Z.; Murphy, K.; Watson, R.W. The role of epithelial-mesenchymal transition drivers ZEB1 and ZEB2 in mediating docetaxel-resistant prostate cancer. Mol. Oncol. 2017, 11, 251-265. [CrossRef]

26. Penrose, D.M.; Glick, B.R. Methods for isolating and characterizing ACC deaminase-containing plant growth-promoting rhizobacteria. Physiol. Plant. 2003, 118, 10-15. [CrossRef] [PubMed]

27. Kuklinsky-Sobral, J.; Araújo, W.L.; Mendes, R.; Geraldi, I.O.; Pizzirani-Kleiner, A.A.; Azevedo, J.L. Isolation and characterization of soybean-associated bacteria and their potential for plant growth promotion. Environ. Microbiol. 2004, 6, 1244-1251. [CrossRef] [PubMed]

28. Bray, R.H.; Kurtz, L.T. Determination of total, organic, and available forms of phosphorus in soils. Soil Sci. 1945, 59, 39-46. [CrossRef]

29. Pikovskaya, R. Mobilization of phosphorus in soil in connection with vital activity of some microbial species. Mikrobiologiya 1948, 17, 362-370.

30. Premono, M.E.; Moawad, A.; Vlek, P. Effect of phosphate-solubilizing Pseudomonas putida on the growth of maize and its survival in the rhizosphere. Indones. J. Crop Sci. 1996, 1113-1123.

31. Narula, N.; Deubel, A.; Gans, W.; Behl, R.K.; Merbach, W.P. Paranodules and colonization of wheat roots by phytohormone producing bacteria in soil. Plant Soil Environ. 2006, 52, 119. [CrossRef]

32. Demutskaya, L.; Kalinichenko, I. Photometric determination of ammonium nitrogen with the Nessler reagent in drinking water after its chlorination. J. Water Chem. Technol. 2010, 32, 90-94. [CrossRef]

33. Schippers, B. Biological control of pathogens with rhizobacteria. Philos. Trans. R. Soc. Lond. B Biol. Sci. 1988, 318, $283-293$.

34. Holt, J.G. The Shorter Bergey's Manual of Determinative Bacteriology, 9th ed.; Williams \& Wilkins: Baltimore, MD, USA, 1994.

35. Holb, I.; Heijne, B.; Jeger, M. Overwintering of conidia of Venturia inaequalis and the contribution to early epidemics of apple scab. Plant Dis. 2004, 88, 751-757. [CrossRef]

36. Liu, X.; Li, R.; Dai, Y.; Chen, X.; Wang, X. Genome-wide identification and expression analysis of the B-box gene family in the Apple (Malus domestica Borkh.) genome. Mol. Genet. Genom. 2018, 293, 303-315. [CrossRef]

37. Nakano, Y.; Asada, K. Hydrogen peroxide is scavenged by ascorbate-specific peroxidase in spinach chloroplasts. Plant Cell Physiol. 1981, 22, 867-880.

38. Radic, S.; Pevalek-Kozlina, B. Differential esterase activity in leaves and roots of Centaurea ragusina L. as a consequence of salinity. Period. Biol. 2010, 112, 253-258.

39. Besford, R.; Syred, A. Effect of phosphorus nutrition on the cellular distribution of acid phosphatase in the leaves of Lycopersicon esculentum L. Ann. Bot. 1979, 43, 431-435. [CrossRef]

40. Kunst-Wilson, W.R.; Zajonc, R.B. Affective discrimination of stimuli that cannot be recognized. Science 1980, 207, 557-558. [CrossRef]

41. Liu, J.; Ridgway, H.J.; Jones, E.E. Apple endophyte community is shaped by tissue type, cultivar and site and has members with biocontrol potential against Neonectria ditissima. J. Appl. Microbiol. 2020, 128, 1735-1753. [CrossRef]

42. Christakis, C.A.; Geaskalogiannis, G.; Chatzaki, A.; Markakis, M.A.; Mermigka, G.; Sagia, A.; Rizzo, G.F.; Catara, V.; Lagkouvardos, T.; Studholme, D.J. Endophytic Bacterial Isolates from Halophytes Demonstrate Phytopathogen Biocontrol and Plant Growth Promotion Under High Salinity. Front. Microbiol. 2021, 12, 1001. [CrossRef] [PubMed]

43. Rodríguez-Calzada, T.; Qian, M.; Strid, Å.; Neugart, S.; Schreiner, M.; Torres-Pacheco, I.; Guevara-González, R.G. Effect of UV-B radiation on morphology, phenolic compound production, gene expression, and subsequent drought stress responses in chili pepper (Capsicum annuum L.). Plant Physiol. Biochem. 2019, 134, 94-102. [CrossRef] 
44. Li, H.Y.; Wei, D.; Shen, M.; Zhou, Z. Endophytes and their role in phytoremediation. Fungal Divers. 2012, 54, 11-18. [CrossRef]

45. Gómez-Lama Cabanás, C.; Schilirò, E.; Valverde-Corredor, A.; Mercado-Blanco, J. The biocontrol endophytic bacterium Pseudomonas fluorescens PICF7 induces systemic defense responses in aerial tissues upon colonization of olive roots. Front. Microbiol. 2014, 5, 427. [CrossRef]

46. Liu, Z.; Zhou, J.; Li, Y.; Wen, J.; Wang, R. Bacterial endophytes from Lycoris radiata promote the accumulation of Amaryllidaceae alkaloids. Microbiol. Res. 2020, 239, 126501. [CrossRef]

47. Zhang, J.; Zhang, C.; Yang, J.; Zhang, R.; Gao, J.; Zhao, X.; Zhao, J.; Zhao, D.; Zhang, X. Insights into endophytic bacterial community structures of seeds among various Oryza sativa L. rice genotypes. J. Plant Growth Regul. 2019, 38, 93-102. [CrossRef]

48. Szymańska, S.; Płociniczak, T.; Piotrowska-Seget, Z.; Złoch, M.; Ruppel, S.; Hrynkiewicz, K. Metabolic potential and community structure of endophytic and rhizosphere bacteria associated with the roots of the halophyte Aster tripolium L. Microbiol. Res. 2016, 182, 68-79. [CrossRef]

49. Arnold, A.E.; Lutzoni, F. Diversity and host range of foliar fungal endophytes: Are tropical leaves biodiversity hotspots? Ecology 2007, 88, 541-549. [CrossRef]

50. Garcia, K.; Zimmermann, S.D. The role of mycorrhizal associations in plant potassium nutrition. Front. Plant Sci. 2014, 5, 337. [CrossRef]

51. Zinniel, D.K.; Lambrecht, P.; Harris, N.B.; Feng, Z.; Kuczmarski, D.; Higley, P.; Ishimaru, C.A.; Arunakumari, A.; Barletta, R.G.; Vidaver, A.K. Isolation and characterization of endophytic colonizing bacteria from agronomic crops and prairie plants. Appl. Environ. Microbiol. 2002, 68, 2198-2208. [CrossRef]

52. Papik, J.; Folkmanova, M.; Polivkova-Majorova, M.; Suman, J.; Uhlik, O. The invisible life inside plants: Deciphering the riddles of endophytic bacterial diversity. Biotechnol. Adv. 2020, 44, 107614. [CrossRef]

53. Trivedi, P.; Mattupalli, C.; Eversole, K.; Leach, J.E. Enabling sustainable agriculture through understanding and enhancement of microbiomes. New Phytol. 2021, 230, 2129-2147. [CrossRef]

54. Khan, M.A.; Asaf, S.; Khan, A.L.; Adhikari, A.; Jan, R.; Ali, S.; Imran, M.; Kim, K.M.; Lee, I.J. Plant growth-promoting endophytic bacteria augment growth and salinity tolerance in rice plants. Plant Biol. 2020, 22, 850-862. [CrossRef]

55. De Souza, J.T.; Silva, A.C.; de Jesus Santos, A.F.; Santos, P.O.; Alves, P.S.; Cruz-Magalhães, V.; Marbach, P.A.; Loguercio, L.L. Endophytic bacteria isolated from both healthy and diseased Agave sisalana plants are able to control the bole rot disease. Biol. Control 2021, 157, 104575. [CrossRef]

56. Kaspar, F.; Neubauer, P.; Gimpel, M. Bioactive secondary metabolites from Bacillus subtilis: A comprehensive review. J. Nat. Prod. 2019, 82, 2038-2053. [CrossRef] [PubMed]

57. Gaby, J.C.; Buckley, D.H. A comprehensive aligned nifH gene database: A multipurpose tool for studies of nitrogen-fixing bacteria. Database 2014, bau001. [CrossRef] [PubMed]

58. Afzal, I.; Shinwari, Z.K.; Sikandar, S.; Shahzad, S. Plant beneficial endophytic bacteria: Mechanisms, diversity, host range and genetic determinants. Microbiol. Res. 2019, 221, 36-49. [CrossRef] [PubMed]

59. Xie, J.; Xu, W.; Zhang, M.; Qiu, C.; Liu, J.; Wisniewski, M.; Ou, T.; Zhou, Z.; Xiang, Z. The impact of the endophytic bacterial community on mulberry tree growth in the Three Gorges Reservoir ecosystem, China. Environ. Microbiol. 2021, 23, 1858-1875. [CrossRef] [PubMed]

60. Padder, S.A.; Dar, G.H.; Mohiddin, F.A.; Shah, M.D. Characterization and plant growth promoting aspects of a novel phosphate solubilizing brown sarson endophyte Pseudomonas fluorescens strain smppsap5 isolated from Northern Himalayas of India. J. Pure Appl. Microbiol. 2016, 10, 2003-2018.

61. Biessy, A.; Novinscak, A.; Blom, J.; Léger, G.; Thomashow, L.S.; Cazorla, F.M.; Josic, D.; Filion, M. Diversity of phytobeneficial traits revealed by whole-genome analysis of worldwide-isolated phenazine-producing Pseudomonas spp. Environ. Microbiol. 2019, 21, 437-455.

62. Rana, K.L.; Kour, D.; Kaur, T.; Devi, R.; Yadav, A.; Yadav, A.N. Bioprospecting of endophytic bacteria from the Indian Himalayas and their role in plant growth promotion of maize (Zea mays L.). J. Appl. Biol. Biotechnol. 2021, 9, 41-50.

63. Dubey, A.; Saiyam, D.; Kumar, A.; Hashem, A.; Allah, E.F.A.; Khan, M.L. Bacterial Root Endophytes: Characterization of Their Competence and Plant Growth Promotion in Soybean (Glycine max (L.) (Merr.) under Drought Stress. Int. J. Environ. Res. Public Health 2021, 18, 931. [CrossRef]

64. Prasad, M.; Srinivasan, R.; Chaudhary, M.; Choudhary, M.; Jat, L.K. Plant growth promoting rhizobacteria (PGPR) for sustainable agriculture: Perspectives and challenges. In PGPR Amelioration in Sustainable Agriculture; Elsevier: Amsterdam, The Netherlands, 2019; pp. 129-157.

65. Clifton, M.C.; Rupert, P.B.; Hoette, T.M.; Raymond, K.N.; Abergel, R.J.; Strong, R.K. Parsing the functional specificity of Siderocalin/Lipocalin 2/NGAL for siderophores and related small-molecule ligands. J. Struct. Biol. X 2019, 2, 100008. [CrossRef]

66. Tilocca, B.; Cao, A.; Migheli, Q. Scent of a killer: Microbial volatilome and its role in the biological control of plant pathogens. Front. Microbiol. 2020, 11, 41. [CrossRef]

67. Kumar, V.; Jain, L.; Jain, S.K.; Chaturvedi, S.; Kaushal, P. Bacterial endophytes of rice (Oryza sativa L.) and their potential for plant growth promotion and antagonistic activities. S. Afr. J. Bot. 2020, 134, 50-63. [CrossRef]

68. Schneider, N.O.; Tassoulas, L.J.; Zeng, D.; Laseke, A.J.; Reiter, N.J.; Wackett, L.P.; Maurice, M.S. Solving the conundrum: Widespread proteins annotated for urea metabolism in bacteria are carboxyguanidine deiminases mediating nitrogen assimilation from guanidine. Biochemistry 2020, 59, 3258-3270. [CrossRef] 
69. Krishnamoorthy, A.; Agarwal, T.; Kotamreddy, J.N.; Bhattacharya, R.; Mitra, A.; Maiti, T.K.; Maiti, M.K. Impact of seed-transmitted endophytic bacteria on intra-and inter-cultivar plant growth promotion modulated by certain sets of metabolites in rice crop. Microbiol. Res. 2020, 241, 126582. [CrossRef]

70. Fierer, N.; Bradford, M.A.; Jackson, R.B. Toward an ecological classification of soil bacteria. Ecology 2007, 88, 1354-1364. [CrossRef]

71. Bardhan, S.; Jose, S.; Jenkins, M.A.; Webster, C.R.; Udawatta, R.P.; Stehn, S.E. Microbial community diversity and composition across a gradient of soil acidity in spruce-fir forests of the southern Appalachian Mountains. Appl. Soil Ecol. 2012, 61, 60-68. [CrossRef]

72. Jimenez-Sanchez, C.; Hanlon, R.; Aho, K.A.; Powers, C.; Morris, C.E.; Schmale, D.G. Diversity and ice nucleation activity of microorganisms collected with a small unmanned aircraft system (sUAS) in France and the United States. Front. Microbiol. 2018, 9, 1667. [CrossRef]

73. Huang, X.; Ren, J.; Li, P.; Feng, S.; Dong, P.; Ren, M. Potential of microbial endophytes to enhance the resistance to postharvest diseases of fruit and vegetables. J. Sci. Food Agric. 2021, 101, 1744-1757. [CrossRef]

74. Delgado-Ramírez, C.S.; Hernández-Martínez, R.; Sepúlveda, E. Rhizobacteria Associated with a Native Solanaceae Promote Plant Growth and Decrease the Effects of Fusariumoxysporum in Tomato. Agronomy 2021, 11, 579. [CrossRef]

75. Rajkumari, J.; Pandey, P. Genomic Insights and Comparative Genomics of Bacillus Species Having Diverse Mechanisms of Biocontrol against Fungal Phytopathogens. In Bacilli and Agrobiotechnology: Phytostimulation and Biocontrol; Springer: Cham, Switzerland, 2019; pp. 217-237.

76. Du, W.; Yao, Z.; Li, J.; Sun, C.; Xia, J.; Wang, B.; Shi, D.; Ren, L. Diversity and antimicrobial activity of endophytic fungi isolated from Securinega suffruticosa in the Yellow River Delta. PLoS ONE 2020, 15, e0229589. [CrossRef]

77. Meena, M.; Swapnil, P.; Divyanshu, K.; Kumar, S.; Harish; Tripathi, Y.N.; Zehra, A.; Marwal, A.; Upadhyay, R.S. PGPR-mediated induction of systemic resistance and physiochemical alterations in plants against the pathogens: Current perspectives. J. Basic Microbiol. 2020, 60, 828-861.

78. Dinesh, R.; Srinivasan, V.; Sheeja, T.E.; Anandaraj, M.; Srambikkal, H. Endophytic actinobacteria: Diversity, secondary metabolism and mechanisms to unsilence biosynthetic gene clusters. Crit. Rev. Microbiol. 2017, 43, 546-566. [CrossRef] 